\title{
The Global Entry of New Pharmaceuticals: A Joint Investigation of Launch Window and Price
}

\author{
Isabel Verniers, Stefan Stremersch, and Christophe Croux
}

\begin{tabular}{|l|l|}
\hline \multicolumn{2}{|l|}{ ERIM REPORT SERIES RESEARCH IN MANAGEMENT } \\
\hline ERIM Report Series reference number & ERS-2011-010-MKT \\
\hline Publication & May 2011 \\
\hline Number of pages & 52 \\
\hline Persistent paper URL & http://hdl.handle.net/1765/23488 \\
\hline Email address corresponding author & verniers@ese.eur.nl \\
\hline Address & Erasmus Research Institute of Management (ERIM) \\
& RSM Erasmus University / Erasmus School of Economics \\
& Erasmus Universiteit Rotterdam \\
& P.O.Box 1738 \\
& 3000 DR Rotterdam, The Netherlands \\
& Phone: + 31 10 408 1182 \\
& Fax: + 31 10 408 9640 \\
& Email: info@erim.eur.nl \\
& Internet: www.erim.eur.nl \\
\hline
\end{tabular}

Bibliographic data and classifications of all the ERIM reports are also available on the ERIM website: www.erim.eur.nl 


\section{ERASMUS RESEARCH INSTITUTE OF MANAGEMENT}

\section{REPORT SERIES}

\section{RESEARCH IN MANAGEMENT}

\begin{tabular}{|l|l|}
\hline ABSTRACT AND KEYWORDS \\
\hline Abstract & $\begin{array}{l}\text { Research on the launch of new products in the international realm is scarce. The present paper } \\
\text { is the first to document how launch window (difference in months between the first worldwide } \\
\text { launch and the subsequent launch in a specific country) and launch price are interrelated and } \\
\text { how regulation influences both launch window and launch price. The research context is the } \\
\text { global - 50 countries worldwide - launch of } 58 \text { new ethical drugs across } 29 \text { therapeutic areas. } \\
\text { We show that the fastest launch occurs when the launch price is moderately high and the } \\
\text { highest launch price occurs at a launch window of 85 months. We find that the health regulator } \\
\text { acts strategically in that the extent to which it delays the launch of a new drug increases with the } \\
\text { price of the new drug. We also find that regulation overall increases the launch window, except } \\
\text { for patent protection. Surprisingly, regulation does not directly impact launch price. The } \\
\text { descriptive information on average launch window and launch price and the interconnection } \\
\text { between launch window and launch price allows managers in ethical drug companies to build } \\
\text { more informed decisions for international market entry. This study also provides public policy } \\
\text { analysts with more quantitative evidence regarding launch window and launch price on a broad } \\
\text { sample of countries and categories. }\end{array}$ \\
\hline Free Keywords & $\begin{array}{l}\text { entry timing, international new product launch, launch price, launch window, pharmaceutical, } \\
\text { regulation }\end{array}$ \\
\hline Availability & $\begin{array}{l}\text { The ERIM Report Series is distributed through the following platforms: } \\
\text { Academic Repository at Erasmus University (DEAR), DEAR ERIM Series Portal } \\
\text { Social Science Research Network (SSRN), SSRN ERIM Series Webpage } \\
\text { Research Papers in Economics (REPEC), REPEC ERIM Series Webpage }\end{array}$ \\
\hline Classifications & $\begin{array}{l}\text { The electronic versions of the papers in the ERIM report Series contain bibliographic metadata } \\
\text { by the following classification systems: } \\
\text { Library of Congress Classification, (LCC) LCC Webpage } \\
\text { Journal of Economic Literature, (JEL), JEL Webpage } \\
\text { ACM Computing Classification System CCS Webpage } \\
\text { Inspec Classification scheme (ICS), ICS Webpage }\end{array}$ \\
\hline
\end{tabular}




\title{
The Global Entry of New Pharmaceuticals: A Joint Investigation of Launch Window and Price
}

\author{
Isabel Verniers ${ }^{\mathrm{a}, \mathrm{b},{ }^{*}}$, Stefan Stremersch $^{\mathrm{a}, \mathrm{c}}$ and Christophe Croux $^{\mathrm{d}}$
}

${ }^{\text {a }}$ Erasmus School of Economics, Erasmus University Rotterdam, Burgemeester Oudlaan 50, P.O. Box

1738, 3000 DR Rotterdam, the Netherlands

${ }^{\mathrm{b}}$ Faculty of Economics and Business Administration, Ghent University, Tweekerkenstraat 2, 9000 Gent, Belgium

${ }^{\mathrm{c}}$ IESE Business School, Universidad de Navarra, Avenida Pearson 21, 08034 Barcelona, Spain

${ }^{\mathrm{d}}$ Faculty of Business and Economics, Catholic University of Leuven, Naamsestraat 69, 3000 Leuven,

Belgium

* Corresponding author. Erasmus School of Economics, Erasmus University Rotterdam, the Netherlands.

Tel.: + 3110 408.13.11; Fax: + 3110 408.91.69; E-mail address: verniers@ese.eur.nl 


\title{
The Global Entry of New Pharmaceuticals: A Joint Investigation of Launch Window and Price
}

\begin{abstract}
Research on the launch of new products in the international realm is scarce. The present paper is the first to document how launch window (difference in months between the first worldwide launch and the subsequent launch in a specific country) and launch price are interrelated and how regulation influences both launch window and launch price. The research context is the global50 countries worldwide - launch of 58 new ethical drugs across 29 therapeutic areas. We show that the fastest launch occurs when the launch price is moderately high and the highest launch price occurs at a launch window of 85 months. We find that the health regulator acts strategically in that the extent to which it delays the launch of a new drug increases with the price of the new drug. We also find that regulation overall increases the launch window, except for patent protection. Surprisingly, regulation does not directly impact launch price. The descriptive information on average launch window and launch price and the interconnection between launch window and launch price allows managers in ethical drug companies to build more informed decisions for international market entry. This study also provides public policy analysts with more quantitative evidence regarding launch window and launch price on a broad sample of countries and categories.
\end{abstract}

Keywords: entry timing, international new product launch, launch price, launch window, pharmaceutical, regulation. 


\section{Introduction}

Marketing scholars have always posed a strong interest in the launch of innovations (for examples, see Golder \& Tellis, 1993; Shankar, Carpenter, \& Krishnamurthi, 1998 and 1999). However, research on the launch of new products in the international realm is scarce. Rare exceptions focus: (1) on the choice between a waterfall and a sprinkler strategy in international entry (Kalish, Mahajan, \& Muller, 1995; Libai, Muller, \& Peres, 2005; Stremersch \& Tellis, 2004; Tellis, Stremersch \& Yin, 2003); and (2) whether products diffuse faster in lead countries (in which the product was introduced first) than in lag countries (in which the product was subsequently introduced) (e.g. Dekimpe, Parker, \& Sarvary, 2000; Eliashberg \& Helsen, 1996).

The lack of attention to international product entry decisions contrasts sharply with the high relevance that international launch time decisions have for today's globally operating firms. The commercialization or launch phase is an important phase for a company (Hultink, Griffin, Robben, \& Hart, 1998), in which it makes decisions on launch time and price, both of which have large implications for future profits (Gregson, Sparrowhawk, Mauskoph, \& Paul, 2005; Hultink et al., 1998; Urban \& Hauser, 1993). In essence, launch time and price are important determinants of the evolution and distribution of cash flows across time and countries.

In the pharmaceutical market - the context of the present paper - regulatory bodies such as the FDA (the Food and Drug Administration) and EMEA (the European Medicines Evaluation Agency; the European counterpart of the FDA) review and approve a new drug's effectiveness and safety. After scientific approval, the firm negotiates about market access with local health regulators (typically, at the country level), to jointly determine launch time and launch price, even though they potentially may have opposite interests. Ethical drug firms (firms that sell 
prescription drugs) aim to recoup $R \& D$ investments through early access (i.e. a long life cycle under patent protection) and a high price, both of which have an important impact on ethical drug companies' bottom line (Boulding \& Christen, 2003; Danzon, Wang, \& Wang, 2005; Wagner \& McCarthy, 2004). Health regulators wish to contain health costs, but at the same time make new life-enhancing and life-saving drugs available to the population (Danzon et al., 2005). To contain health budgets, many countries have introduced some form of regulation that restricts a firm in setting prices freely. For instance, Spain has set a threshold (12-18\% of allowable cost) that regulates the profit margins ethical drug firms can make, which may put downward pressure on prices in Spain and make manufacturers less keen to enter Spain promptly (Kanavos, 2001).

Prior studies (Danzon et al., 2005; Kyle, 2006 and 2007; Lanjouw, 2005) have examined launch timing, without accounting for launch price. Other authors have studied launch price, without accounting for launch timing (e.g. Berndt, 2000; Danzon \& Chao, 2000a; Danzon \& Furukawa, 2003 and 2006; Danzon \& Kim, 1998; Huttin, 1999). The present paper examines how launch timing and launch price interrelate and how regulation affects both decisions. In terms of launch timing, we focus on launch window, which is the difference in months between the first worldwide launch and the subsequent launch in a specific country. We gathered monthly launch windows and launch prices for 58 new drugs launched by ethical drug companies, across 29 different therapeutic categories and 50 - both developed and developing (also see, Burgess \& Steenkamp, 2006) - countries worldwide, yielding a rich dataset, on both the drug- and countrylevel. We simultaneously estimate a launch window equation and a launch price equation, capturing the endogeneity of these decisions.

We find that launch price has a U-shaped effect on launch window, while launch window has an inverted U-shaped effect on launch price. In our sample, the fastest launch occurs when 
the launch price is moderately high and the highest price occurs at a launch window of about 85 months. We also find that health regulators act strategically as the launch window increases with the price of the new drug. Overall, we find that regulation increases launch window. Contrary to our expectations, we do not find that regulation directly influences launch prices. Interestingly, such regulations may serve to reduce prices faster over the life cycle, rather than the launch price per se, for which Stremersch and Lemmens (2009) provide anecdotical evidence, based on the price pattern they observe in Belgium, Canada, Germany, Switzerland, UK and US, in their Figure 1. Our findings are new to the literature, are based on a large sample of new pharmaceutical drugs, and have high relevance for both firms and regulators. Within the bounds of the data, our model can give insights into hypothetical situations, such as, how a further delay in the entry of a new drug may affect launch price. The descriptive information on average launch window and launch price and the interconnection between launch window and launch price allows managers in ethical drug companies to build more informed decisions for international market entry. This study also provides public policy analysts with more quantitative evidence regarding launch window and price on a broad sample of countries and categories.

\section{Theoretical Background}

This section first reviews past literature on international launch window and launch price, both in marketing and economics. Then, we develop hypotheses on the interrelationship between launch window and launch price and on the effect of regulation on launch window and launch price. We end with a discussion of the other variables that may affect launch window and launch price, which we control for in our estimation. 


\subsection{Past Literature on International Launch Window and Price}

Table 1 summarizes prior literature on international launch of new products ${ }^{1}$ and international pricing, published in economics and marketing. From Table 1, we learn that previous studies have not yet considered the interrelationship between launch window and launch price. Prior research on international launch has focused on identifying determinants of launch windows. Prior research on international pricing mostly examines bilateral price comparisons, while examining the determinants of such differences only in a few cases. In such papers, scholars have examined the influence of competition or a firm's country of origin on international pricing differences. We also learn from Table 1 that our study is one of the most comprehensive ever on this topic, given the number of new products and countries studied and the richness of the covariate set included in our model.

\subsection{The Interrelationship of Launch Window and Launch Price}

In the pharmaceutical industry, launch window and launch price are the result of an undisclosed negotiation process between health regulators (e.g. governments and government institutes), on the one hand, and ethical drug companies, on the other hand (Danzon et al., 2005; Garattini \& Ghislandi, 2007). The launch window and launch price are important to ethical drug companies as they affect the evolution and distribution of cash flows over time and countries. This incoming cash flow for firms corresponds to healthcare spending for health regulators.

\footnotetext{
${ }^{1}$ We exclude studies on within-country order-of-entry or on firm entry from this overview.
} 


\begin{tabular}{|c|c|c|c|c|c|c|c|c|}
\hline Reference & $\begin{array}{l}\text { Dependent } \\
\text { Variable }\end{array}$ & $\begin{array}{c}\text { Focal } \\
\text { Independent Variables }\end{array}$ & $\begin{array}{l}\text { Launch } \\
\text { Window } \\
\text { Modeled? }\end{array}$ & $\begin{array}{l}\text { Launch } \\
\text { Price } \\
\text { Modeled? }\end{array}$ & $\begin{array}{l}\text { Number of } \\
\text { Geographic } \\
\text { Markets }\end{array}$ & $\begin{array}{l}\text { Number of } \\
\text { Products }\end{array}$ & Product Markets & Key Findings \\
\hline $\begin{array}{l}\text { Bolton \& Myers } \\
\quad(2003)\end{array}$ & Price sensitivity & $\begin{array}{l}\text { Service quality, type, } \\
\text { and support }\end{array}$ & No & No & 7 & 1 & Software systems & $\begin{array}{l}\text { Service quality, type, and support have a significant positive influence on } \\
\text { price elasticities. This effect depends on national and regional variables. }\end{array}$ \\
\hline $\begin{array}{l}\text { Chintagunta \& } \\
\text { Desiraju (2005) }\end{array}$ & Price level & Home country of firm & No & No & 5 & 3 & Pharmaceuticals & $\begin{array}{l}\text { Firms charge a higher price for drugs in their home country. These firms } \\
\text { behave more aggressively towards their competitors in their home } \\
\text { market. }\end{array}$ \\
\hline $\begin{array}{l}\text { Danzon \& Chao } \\
\quad(2000 \mathrm{a})\end{array}$ & $\begin{array}{l}\text { Bilateral drug price } \\
\text { indexes }\end{array}$ & Competition & No & No & 7 & 171 & Pharmaceuticals & $\begin{array}{l}\text { Within-country price competition influences differences in prices across } \\
\text { countries. }\end{array}$ \\
\hline $\begin{array}{c}\text { Danzon \& } \\
\text { Furukawa }(2003)\end{array}$ & $\begin{array}{l}\text { Bilateral drug price } \\
\text { indexes }\end{array}$ & l & No & No & 8 & 249 & Pharmaceuticals & Prices in Japan and the US are higher than in other countries. \\
\hline $\begin{array}{l}\text { Danzon, Wang, \& } \\
\text { Wang (2005) }\end{array}$ & Launch window & $\begin{array}{l}\text { Market size } \\
\text { Competition } \\
\text { Firm characteristics }\end{array}$ & Yes & No & 25 & 85 & Pharmaceuticals & $\begin{array}{l}\text { Countries with lower expected prices or smaller expected market size } \\
\text { have larger launch windows (i.e., longer launch delays). }\end{array}$ \\
\hline $\begin{array}{l}\text { Dawar \& Parker } \\
\quad \text { (1994) }\end{array}$ & $\begin{array}{l}\text { Relative and } \\
\text { absolute importance } \\
\text { of price as a quality } \\
\text { signal }\end{array}$ & $\begin{array}{l}\text { National (workforce, } \\
\text { culture, ...) and } \\
\text { individual } \\
\text { characteristics }\end{array}$ & No & No & 38 & 1 & $\begin{array}{l}\text { Consumer } \\
\text { electronics }\end{array}$ & $\begin{array}{l}\text { Price as a quality signal does not depend on culture but is likely to } \\
\text { depend on individual characteristics. }\end{array}$ \\
\hline $\begin{array}{l}\text { Ekelund \& Persson } \\
(2003)\end{array}$ & Price levels & Competition & No & Yes & 1 & 246 & Pharmaceuticals & Price regulation in Sweden discourages price competition. \\
\hline $\begin{array}{c}\text { Goldberg \& } \\
\text { Verboven }(2001)\end{array}$ & Price levels & $\begin{array}{l}\text { Firm characteristics } \\
\text { (country of origin, costs, } \\
\text { import quota } \\
\text { constraints) }\end{array}$ & No & No & 5 & $\begin{array}{l}\text { Approx. } \\
150\end{array}$ & Cars & $\begin{array}{l}\text { Higher prices are partially attributable to a preference for domestic } \\
\text { brands. }\end{array}$ \\
\hline $\begin{array}{l}\text { Kalish, Mahajan, \& } \\
\quad \text { Muller (1995) }\end{array}$ & Launch window & $\begin{array}{l}\text { Competition, size and } \\
\text { growth of foreign } \\
\text { market, fixed cost of } \\
\text { entry, product life cycle, } \\
\text { innovativeness } \\
\end{array}$ & Yes & No & $\begin{array}{l}\text { No empirical } \\
\text { data }\end{array}$ & $\begin{array}{l}\text { No } \\
\text { empirical } \\
\text { data }\end{array}$ & No empirical data & $\begin{array}{l}\text { A waterfall strategy is preferred under certain conditions such as high } \\
\text { fixed entry costs and low competitive pressure. }\end{array}$ \\
\hline Kyle (2006) & Launch window & Firm characteristics & Yes & No & 7 & 1,482 & Pharmaceuticals & $\begin{array}{l}\text { New drugs are launched faster in countries where the headquarter of the } \\
\text { company is located. }\end{array}$ \\
\hline Kyle (2007) & Launch window & Regulation & Yes & No & 25 & 1,444 & Pharmaceuticals & Countries with price controls show larger launch windows. \\
\hline $\begin{array}{l}\text { Lu \& Comanor } \\
\text { (1998) }\end{array}$ & Price levels & Competition & No & Yes & 1 & 144 & Pharmaceuticals & $\begin{array}{l}\text { The number of branded substitutes has a significant negative effect on } \\
\text { launch prices. }\end{array}$ \\
\hline Rojas (2009) & Price levels & Company type & No & No & 6 & 641 & Pharmaceuticals & $\begin{array}{l}\text { Significant differences in the prices of identical drugs exist across Central } \\
\text { American countries. }\end{array}$ \\
\hline This study & $\begin{array}{l}\text { Launch Window } \\
\& \text { a } \\
\text { Launch Price }\end{array}$ & $\begin{array}{c}\text { Regulation } \\
\text { (economy, } \\
\text { demography, } \\
\text { competition, culture, } \\
\text { drug, firm) }\end{array}$ & Yes & Yes & 50 & 58 & Pharmaceuticals & $\begin{array}{l}\text { Launch window has an inverted } U \text {-shaped effect on launch price, } \\
\text { whereas launch price has a } U \text {-shaped effect on launch window. We } \\
\text { also find that regulation overall increases the launch window, except } \\
\text { for patent protection. Surprisingly, regulation does not directly } \\
\text { impact launch price. }\end{array}$ \\
\hline
\end{tabular}

Table 1: Overview of prior studies on international launch window and pricing and a comparison with the present study 
Beyond containing healthcare spending, health regulators may also have the population's access to state-of-the-art healthcare as an objective. The combination of both objectives presents health regulators with a formidable challenge, because new drugs promise greater medical benefits, but typically at a higher price than prior alternatives. Thus, both from a regulator's and from a firm's perspective, launch price and launch window may be interrelated.

The relationship between launch window and launch price has three distinct aspects: (1) the causal effect of launch price on launch window; (2) the causal effect of launch window on launch price; and (3) the joint determination of both. Next, we develop hypotheses on the first two aspects, while we will control for the simultaneity in the launch window and launch price decisions in our empirical tests.

Let's first consider the effect launch price may have on launch window. If the launch price of a new drug is high, the drug represents, ceteris paribus, a more attractive market opportunity for the ethical drug company, than when the launch price of a new drug is low (Financial Times, 2007), making them more keen to launch fast to maximize the net present value of its future revenue streams (Gregson et al. 2005). This argument is in line with Giaccotto, Santerre, \& Vernon (2005) and Ridley (2007), who documented earlier that low prices may harm the worldwide launch of new drugs. Ethical drug firms may also be concerned that launching fast in low-price countries may drive down the drug's price in high-price countries in the future (Gregson et al., 2005).

Health regulators, ceteris paribus, may be increasingly negatively disposed to the launch of a new drug as it gets more expensive, given concerns over increasing healthcare budgets of which pharmaceutical drug expenses are a substantial part (Cohen, Faden, Predaris, \& Young, 2007; Gregson et al., 2005). Healthcare budgets are under pressure, all around the world - in 
many developed countries because of an ageing population, in many developing countries, because of a growing population. The increased budget pressure has lowered health regulators' aspirations to provide fast market access to expensive new drugs (Comanor \& Schweitzer, 2007). Health regulators may soften the impact of expensive drugs on their budget by delaying their entry, either explicitly in the price negotiation, e.g. by not promptly agreeing to the manufacturer's proposed price (Danzon et al. 2005) or by increasing the administrative approval burden on expensive medication.

Given the opposing logic between firms and regulators, we propose a curvilinear relationship between launch price and launch window, in which launch occurs fastest at moderate launch prices. The reason is that a very low launch price may be unacceptable to the firm, while a very high price may be unacceptable to the regulator. In both cases, either the firm or the regulator will seek to delay launch to put pressure on the other party in the negotiation. Both parties will only align on a quick launch, if the price is moderate. This expectation is consistent with earlier findings in the negotiation literature that challenging, yet attainable, goals lead to an integrative solution for both parties involved (McAlister, Bazerman, \& Fader, 1986).

In sum, we hypothesize:

\section{H1: Launch price has a $U$-shaped effect on launch window.}

Next, let's consider the effect of launch window on launch price. New drugs typically receive a fixed patent-protection period of 20 years from initial filing for approval of a new drug (Danzon et al. 2005; Dimasi, Hansen, \& Grabowski, 2003; Kyle, 2006). After this initial filing, it typically takes between 8 and 12 years for a drug to be developed and clinically tested, before it is approved for commercial use by organizations such as EMEA in Europe and the FDA in the U.S. After approval, the applicant has a monopoly on marketing the approved substance for the 
remaining years of the patent life cycle, on average for 11 years (Grabowski \& Kyle 2007). An ethical drug firm aims to recuperate its R\&D expenditures - discovery and the different stages of clinical development and testing - and market entry expenditures - local cost effectiveness studies, conferences with key opinion leaders and physician detailing, among others - over the life cycle of a drug. An ethical drug firm generates the dominant share of its profits when the drug is still under patent protection and has no bioequivalent competition (Lu \& Comanor, 1998). Pharmaceutical companies operating in an international context launch at different times in different countries worldwide because of different approval and administrative procedures or because of differences in countries' market attractiveness. The larger the launch window becomes, e.g. because of long administrative procedures, the less time under patent protection remains for the firm in the global context to recuperate its expenses for the drug, and the more the firm will insist on a higher price to make up for the lost time under exclusivity.

The health regulators may show an opposite reaction to launch window. As time goes by, more information on the drug spreads around the world and the drug loses its novelty. Generic alternatives become a more prominent benchmark as patent expiry comes closer (Morton, 1999), and a larger volume of independent studies in foreign populations outside a clinical setting (i.e., when the drug is commercially available on foreign markets) may call into question the drug's efficacy (e.g. Duloxetine) or raise important safety issues (e.g. Vioxx) (see Sood \& Stremersch, 2010). Thus, the health regulator's willingness to pay for the drug may decrease over time.

Combining both arguments, we propose an inversed U-shaped effect of launch window and launch price, in which launch price is highest at moderate levels of launch window. At moderate levels of launch window, the firm can still make money under patent protection if the price is high enough, to make up for local market entry expenditures. At very low levels of 
launch window, the firm will accept a lower launch price more easily, as the drug enjoys a full life under patent protection, by which the firm starts recuperating R\&D expenditures and gains resources for international market access immediately. At very high levels of launch window, the health regulator's reference point will be based on generic drug prices. The firm itself may also already be in "generic" mode as its drug is reaching patent expiration globally and it prepares for generic competition. Therefore, at very high levels of launch window, both will align more easily on a relatively low launch price as a prelude to generic competition.

We hypothesize:

\section{H2: Launch window has an inverted $U$-shaped effect on launch price.}

\subsection{The Effect of Regulation on Launch Window and Launch Price}

To control pharmaceutical spending, many countries apply various forms of regulatory restrictions, which may affect launch window and launch price (Abbott, 1995; Ekelund \& Persson, 2003; Kanavos, 2001; Mossialos, Mrazek, \& Walley, 2004). We discuss each of these regulatory restrictions and their hypothesized effect on launch window and launch price.

\subsubsection{Ex-Manufacturer Price Regulation}

The first regulatory requirement we consider is the presence of ex-manufacturer price control. Ex-manufacturer price control caps the ex-manufacturer price (the price charged by the manufacturer to the wholesaler) of a pharmaceutical product. A country's public health administration determines a maximum price or reservation price that a manufacturer can charge (Danzon et al., 2005). Belgium, Greece and Portugal are examples of countries with a strict exmanufacturer price regulation. Ex-manufacturer price control may slow down market access as it often lengthens the price negotiation process between regulator and manufacturer. Heuer, Mejer, 
\& Neuhaus (2007) and Kyle (2007) found for a limited sample of countries that ex-manufacturer price control delays new drug launch. Furthermore, Mossialos et al. (2004) state - without an empirical test - that countries with such a control are more likely to have lower introductory prices than countries without such a control. Ekelund and Persson (2003) and Lu and Comanor (1998) show that introductory prices are not lower in a country with a price cap regulation than in a country without a price cap regulation. Danzon and Chao (2000b) show across a sample of 7 countries that the prices decline more with molecule age in countries that apply ex-manufacturer price control than in countries that do not apply this control. Although the evidence is mixed, we may expect launch prices to be lower in countries that apply this price control system than in countries that do not apply this price control system.

We hypothesize:

H3: New drugs are launched (a) later and (b) at a lower price in countries with exmanufacturer price regulation than in countries without ex-manufacturer price regulation.

\subsubsection{Profit Regulation}

Public policy administrators may also influence the general price levels of drugs more indirectly by restricting the profits ethical drug firms can obtain. In such regulatory context, drug companies are free to set their own prices but cannot exceed a predetermined profit ceiling (Jacobzone, 2000). The U.K. is a well-known example of a country that applies profit control regulation, in which the government negotiates with individual ethical drug companies on the amount of profit they can make (Borrell, 1999). While the direct effect of profit control on launch window is unexamined by prior scholars, we argue that it may slow down market access. In general, profit contribution by new products is considered to be large (Chandy \& Tellis, 1998). New drugs typically enhance ethical drug firms’ profitability (Wuyts, Dutta, \& 
Stremersch, 2004) and profit controls cap overall profit margins. Therefore, ceteris paribus, ethical drug firms will prefer to sustain mature drugs over launching their newly developed drugs on markets with profit controls (Rapp \& Lloyd, 1994).

The agreed upon return-on-capital threshold due to the profit regulation provides incentives for manufacturers to set their prices so that profits do not exceed this threshold. Exceeding these profit rates can lead to a penalty that forces companies to lower their prices (Novartis, 2004). Therefore, we may expect that companies set lower launch prices for their newly developed drugs in countries that control profit.

Therefore, we hypothesize:

\section{H4: New drugs are launched (a) later and (b) at a lower price in countries with profit regulation than in countries without profit regulation.}

\subsubsection{Cross-Country Reference Pricing}

The third regulatory restriction we consider is whether the regulator demands information from the manufacturer on drug prices in other countries or not. Under this regulation, health regulators require companies to supply information on prices, for the drugs they want to launch, in selected foreign countries, and will cap prices based on that information (Dukes et al. 2003). A good example is Austria where the government asks companies for notification on their ex manufacturer prices in other similar countries.

While the intention of the regulator is to provide another capping mechanism on drug prices, the comparison between countries can create industry concern of a low introductory price to spill over to other countries. Therefore, cross-country reference pricing may show perverse effects (Hunter 2005). First, when a country applies cross-country reference pricing, firms will try to gain market access as early as possible, to avoid as many reference countries as possible. 
Second, cross-country reference pricing may push prices upward, rather than downward. Typically, regulators that seek early drug access are more willing to concede on higher prices. Thus, the likelihood of a reference country having a high price, rather than a low price, is higher early in the life cycle, rather than later. Consequently, the reference set of a country is likely to contain a greater number of high-price than low-price countries, early in the life cycle, as compared to late in the life cycle.

H5: New drugs will be introduced (a) earlier and (b) at a higher price in countries that have a cross-country reference pricing mechanism than in countries that do not have a cross-country reference pricing mechanism.

\subsubsection{Therapeutic Reference Pricing}

Therapeutic reference pricing refers to the presence (or absence) of a system to classify products into clusters based on therapeutic similarity (Danzon and Furukawa 2003). Health regulators set a reference price for each cluster based on a low priced product. If the manufacturer price is set above this reference level, the patient is surcharged. Therapeutic reference pricing is different from ex manufacturer price control in that it concerns the reimbursement level of a drug, rather than its price (Dukes et al. 1998). Germany, the Netherlands and New Zealand are three countries which are especially known for their therapeutic reference pricing system.

Danzon and Furukawa (2003) claim that therapeutic reference pricing causes price pressure. The reason is that drugs, of which the price tops the reference point, require substantial co-pay by the patient, making the drug less attractive. Danzon and Ketcham (2004) show that more stringent systems of therapeutic reference pricing are associated with lower prices as compared to less stringent systems of therapeutic reference pricing. 
Typically, therapeutic referencing would also delay launch as the administrative procedure requires an examination of therapeutic similarities, delaying market access.

H6: New drugs will be introduced (a) later and (b) at a lower price in countries that apply a therapeutic reference pricing system as compared to countries that do not apply a therapeutic reference pricing system.

\subsubsection{Pharmaco-economic Evidence}

Regulators may require pharmaceutical firms to provide pharmaco-economic evidence on their new drug (Dickson et al. 2003). That way, regulators try to establish fair prices on the basis of calculations where the costs of a drug are compared with its direct and indirect benefits. Pharmaco-economic evidence inventories the cost-effectiveness of a treatment with a new drug as the ratio of the cost of treatment (including the drug price, but also for instance, hospital stays, surgery, etc.) to relevant measures of its effect (Garber and Phelps 1997). Australia has one of the most developed systems in this regard (Dukes et al. 2003).

This requirement demands - on top of the clinical evidence provided to gain therapeutic approval by institutes such as FDA or EMEA - evidence on the cost-effectiveness in the local population that needs to be submitted in complicated administrative procedures. Therefore, it often causes a delay in market access, in a fashion similar to therapeutic reference pricing (Wilking and Jönsson 2005). On the positive side, it also makes the market access procedure more evidence-based (Stremersch and Van Dyck 2009), which may effectively yield higher prices, because of stronger clinical evidence.

H7: New drugs will be introduced (a) later and (b) at a higher price in countries that require pharmaco-economic evidence as compared to countries that do not require pharmacoeconomic evidence. 


\subsubsection{Patent protection}

Ethical drug companies find countries that strictly enforce patent protection more attractive than countries that do not strictly enforce patent protection, because such regulation protects them from bio-equivalent, price competition. Thus, a stronger patent protection regulation may encourage ethical drug companies to enter relatively early, as their period of exclusivity after entrance is strongly protected. Furthermore, stronger patent protection may impose a downward pressure on launch prices as pharmaceutical companies can become more lenient on prices as there will be sufficient time left under patent protection to recuperate $R \& D$ expenditures.

H8: New drugs will be introduced (a) earlier and (b) at a lower price in countries with more patent protection as compared to countries with less patent protection.

\subsection{Other Variables ${ }^{2}$}

We control for market size of a country, by including population size and health expenditures per capita, in our model to test the hypotheses above. Firms may be more prompt in their attempts to access large markets, thus decreasing launch window, but they will be less willing to compromise on launch price, as accepting a low price in large markets has large (negative) effects on anticipated profits. Also, health regulators in large markets may be more prompt in allowing new drugs to market, as the number of affected people is larger than in small

\footnotetext{
${ }^{2}$ While unit sales will also affect the evolution and distribution of cash flows across time and countries, we consider its inclusion outside the scope of our study. Its full inclusion would require a model with a much higher complexity that accounts for adoption timing, repeat sales and compliance of patients. While this lower complexity comes at the threat of omitted variable bias, it seems reasonable to assume unit sales is not sensitive to introduction timing in the context of new pharmaceuticals (as documented empirically by Stremersch and Lemmens, 2009), nor is it likely that early unit sales is sensitive to launch price (physicians typically first prescribe a new treatment to patients who were impossible or difficult to treat with previously available alternatives, which makes early market adoption a function of drug efficacy and not much else, as argued in Vakratsas and Kolsarici, 2008).
} 
markets. Firms may be more eager to launch in countries with high health expenditures per capita as these countries may have a more favorable attitude towards new drugs. On the other hand, higher health expenditures per capita could lower health regulators' aspirations to provide fast market access to new drugs (Comanor \& Schweitzer, 2007) or to allow high prices, as they feel a higher budget pressure.

A second set of variables operationalizes a country's national culture, for which we use the four dimensions identified by Hofstede (1980 and 2001): uncertainty avoidance, masculinity, individualism, and power distance. Hofstede (2001) has argued that members of uncertainty avoidant cultures show lower subjective health perceptions, as compared to members of cultures low in uncertainty avoidance (Hofstede, 2001). Low subjective health perceptions may encourage health regulators to allow prompt access to new drugs and be less price-sensitive. Thus, we expect launch window to be smaller and launch price to be higher in uncertainty avoidant countries, as compared to countries low in uncertainty avoidance.

Masculine societies are characterized to a greater extent by assertiveness versus nurturance (Hofstede, 2001). Societies low in nurturance may perceive a lower need for medical care, unless when it is really necessary (Weber, Roberts, \& McDougall Jr., 2000). Health regulators in masculine societies may be more resistant to allow prompt market access and show a lower willingness to pay, as compared to health regulators in feminine societies, especially for drugs that treat non-life-threatening diseases. Thus, we expect that, on the average, launch window is larger and launch price is lower in masculine countries, as compared to feminine countries.

Hofstede (2001) has argued that members of a culture high in individualism show higher satisfaction towards health care and spend more money on healthcare as compared to cultures 
low in individualism. Therefore, we expect a smaller launch window and a higher launch price in individualistic countries, as compared to collectivist countries.

Members of a culture high in power distance perceive a higher degree of inequality in power between themselves and the more powerful party. These societies are, therefore, often more bureaucratic (Hofstede, 2001). Therefore, we expect launch window to be larger in societies high in power distance, as compared to countries low in power distance. We have no ex ante expectation about the influence of power distance on launch price.

Third, we control for the competition a drug faces within a category. The more competing drugs there are in a category, the higher the pressure on the firm to launch fast to secure adoption from newly diagnosed patients, but the lower the pressure on the regulator to grant market access. Strong competition also provides the health regulator with bargaining power to obtain a low price (Ekelund \& Persson, 2003; Lu \& Comanor, 1998). Thus, the effect of competition on launch window is unclear, while we expect the effect of competition on launch price to be negative. The latter expectation is consistent with Chintagunta and Desiraju (2005), who found that prices of drugs across 5 markets are lower when there is more competition.

Fourth, we control for a home country effect on both launch window and launch price. Ethical drug companies' larger familiarity with the home market's therapeutic needs or health regulator's favoritism towards these ethical drug companies may lead to a faster launch (Kyle, 2006) and a higher launch price (Wagner \& McCarthy, 2004).

Fifth, we control for two additional covariates that we expect to influence launch window, but not launch price (Summer and EMEA). As approvals show a seasonal pattern around Summer holidays (Sietsema, 2006), we expect an influence of Summer on launch window. Second, while market access and price negotiations take place at the country-level, the 
drug approval process in Europe is centralized. Given that the launch window (and not launch price) is co-determined by the (scientific) approval date of a new drug, EMEA member states will show greater similarity in launch window than countries that are not a member of EMEA. We expect launch window in EMEA countries to be shorter than in non-EMEA countries, because of administrative efficiencies. We do not expect an influence of EMEA membership on launch price as prices are set at the individual country level. The existence of parallel trade shows that the centralization of the drug approval process in the EMEA zone has not led to uniform prices (Danzon, 1998). We also control for two additional covariates that we expect to influence launch price, but not launch window (daily dosage and inflation rate). We add these two variables to avoid biases in the measure of launch price. The launch price of a drug in grams may be influenced by the drug's defined daily dosage in grams. The launch price of a drug of which a patient needs a low daily dosage may be higher than the launch price of a drug of which a patient needs a high daily dosage. The reason is that health regulators and manufacturers negotiate on price based upon the total therapy cost, irrespective of the dosage quantity, because of the low variable (i.e. manufacturing) costs of the active ingredient in a drug. We also control for the inflation rate to make launch prices comparable across countries and time.

Finally, we include therapeutic category dummy variables. The inclusion of these fixed category effects is in line with previous research on drug's launch window (Danzon et al., 2005; Kyle, 2007; Lanjouw, 2005). Gregson et al. (2005) acknowledge that a country's evaluation of the therapeutic category's importance affects both launch window and price of a new drug in that therapeutic category. For example, the importance of the erectile dysfunction drug category (or other lifestyle drugs) may be judged differently across health regulators from different countries. We explain the operationalization of all variables in section 3.2. 


\section{Data}

In this section, we give an overview of the research context and define the variables, after which we present descriptive statistics of international launch window and launch price patterns.

\subsection{Research Context}

\begin{tabular}{|c|c|c|}
\hline ATC1 and ATC3 Codes & ATC4 Code & Nr of Drugs \\
\hline A Alimentary tract and metabolism & & 12 \\
\hline A2B: drugs for peptic ulcer and reflux disease & $\mathrm{A} 2 \mathrm{BC}$ & 1 \\
\hline A3A: drugs for functional bowel disorder & $\mathrm{A} 3 \mathrm{AE}$ & 1 \\
\hline A4A: antiemetics and antinauseants & A4AA & 2 \\
\hline A7E: intestinal anti-inflammatory agents & A7EC & 1 \\
\hline A8A: antiobesity preparations, excl. diet products & $\mathrm{A} 8 \mathrm{AB}$ & 2 \\
\hline \multirow[t]{2}{*}{ A10B: blood glucose lowering drugs, excl. insulins } & A10BG & 3 \\
\hline & $\mathrm{A} 10 \mathrm{BX}$ & 2 \\
\hline C Cardiovascular system & & 11 \\
\hline C2K: other antihypertensives & $\mathrm{C} 2 \mathrm{KX}$ & 1 \\
\hline C3D: potassium sparing agents & C3DA & 1 \\
\hline C9C: angiotensin II antagonists, plain & C9CA & 4 \\
\hline \multirow[t]{2}{*}{ C10A: lipid modifying agents, plain } & C10AA & 4 \\
\hline & C10AX & 1 \\
\hline G Genito-urinary system and sex hormones & & 9 \\
\hline G3X: other sex hormones and modulators of the genital system & G3XC & 1 \\
\hline \multirow[t]{2}{*}{ G4B: other urologicals, incl. antispasmodics } & G4BD & 2 \\
\hline & G4BE & 5 \\
\hline G4C: drugs used in benign prostatic hypertrophy & G4CB & 1 \\
\hline J Antiinfectives for systemic use & & 19 \\
\hline J1D: other beta-lactam antibacterials & J1DH & 1 \\
\hline J1F: macrolides, lincosamides and streptogramins & J1FA & 1 \\
\hline J1M: quinolone antibacterials & J1MA & 3 \\
\hline J1X: other antibacterials & J1XX & 2 \\
\hline J2A: antimycotics for systemic use & $\mathrm{J} 2 \mathrm{AX}$ & 2 \\
\hline \multirow[t]{5}{*}{ J5A: direct acting antivirals } & $\mathrm{J} 5 \mathrm{AE}$ & 3 \\
\hline & J5AF & 3 \\
\hline & J5AG & 1 \\
\hline & J5AH & 2 \\
\hline & J5AX & 1 \\
\hline R Respiratory system & & 7 \\
\hline R3B: other drugs for obstructive airway diseases, inhalants & R3BB & 1 \\
\hline R3D: other systemic drugs for obstructive airway diseases & $\mathrm{R} 3 \mathrm{DC}$ & 1 \\
\hline R6A: antihistamines for systemic use & R6AX & 5 \\
\hline
\end{tabular}

Table 2: Overview of the categories in our sample 
We obtained data on launch window and launch price for 58 new drugs in 5 anatomical therapeutic classes (WHO Collaboratory Center for Drug Statistics Methodology) and 50 countries (both developed and developing countries) worldwide from IMS Health (see Table 2). ${ }^{3}$

We selected these drugs for several reasons. First, these drugs' retail sales represent more than $90 \%$ of the total sales volume, meaning they are consistently used in the outpatient environment. Second, because our analyses required information on launch window and launch price, we were limited to use the drugs launched as of $02 / 94$ due to data storage procedures of our data supplier IMS Health. Column 1 in Table 2 represents the categories ATC1 and ATC $3^{4}$ to which our drugs belong. Column 2 gives the more specific fourth level ATC code and the last column gives the number of newly launched drugs in our dataset that belong to these categories.

\subsection{Variables}

We operationalize the launch window $\left(L W_{i j}\right)$ of drug $i$ in country $j$ as the difference (in months) between the month in which the drug was launched in the first country worldwide and the month in which the drug was launched in country $j$ (Danzon et al., 2005). The month of launch is the first month in which sales of the new drug are non-zero. As confirmed by IMS Health, our context involves highly regulated markets and firms at the local country level are prepared for launch in terms of product delivery. Therefore, the data are unlikely to be

\footnotetext{
${ }^{3}$ Given the sample of 58 new drugs across 50 countries, there are 2,900 possible drug-country combinations. However, given right censoring in the data, of these 2,900 possible drug-country pairs, 2,045 remain. We will use these 2,045 observations for our descriptives on launch window and price, below. As we will regress launch price and launch window on other country characteristics, such as regulation, which is unavailable for 8 countries (Egypt, Jordan, Kuwait, Lebanon, Peru, Tunisia, Uruguay, and Venezuela), our model estimation is based on 1,711 drugcountry pairs. This number is higher than 1,581 (2,045 - (58 drugs*8 countries)) because some of the right-censored observations overlap with the drug-country observations for which regulatory information is missing.

${ }^{4}$ The number in ATC1 and ATC3 refers to the categorization level. The third level ATC code (ATC3) gives a more specific drug categorization than the first level ATC code (ATC1).
} 
systematically left-censored. If a drug $i$ is launched for the first time worldwide in January 2001 in country X and it is launched subsequently in country Y in June 2001, the launch window of drug $i$ in country $\mathrm{X}$ is equal to zero months and the launch window of drug $i$ in country $\mathrm{Y}$ is equal to five months. The launch price $\left(L P_{i j}\right)$ of drug $i$ in country $j$ is the natural logarithm of the ex-manufacturer price at launch (the selling price charged by the manufacturer to the wholesaler) in U.S. dollars per gram. To make drug prices comparable across countries, the drug prices in local currencies are converted to US dollars using the currency conversion rate at launch. All the drugs in our data were launched for the first time within the period 02/94 to 06/08. However, not all drugs are launched in all 50 countries by the end of our observation window. In other words, our data contain right-censored observations.

While the regulatory environment is intrinsically complex, with subtle differences across countries, empirical analysis demands a clear-cut operationalization of the regulatory environment (e.g. Kyle, 2007; Stremersch \& Lemmens, 2009; Vernon, Golec, \& Keener Hughen, 2006). We measure the regulatory environment, based on prior research (e.g. Kyle, 2007) and practitioner journals (Kanavos, 2001; PhRMA, 2004), using reports by ethical drug companies (e.g. Novartis, 2004), OECD (Jacobzone, 2000) and Urch publishing (Urch, 2001a and 2001b, 2002, and 2005), as well as personal conversations with countries' health ministries, at the time of launch, as follows:

- Ex-manufacturer price regulation: the presence $(=1)$ or absence $(=0)$ of a direct restriction of price levels by the regulator (Heuer et al., 2007; Kyle, 2007), denoted REGPRICECONTROL;

- Profit control regulation: the presence $(=1)$ or absence $(=0)$ of a threshold on the profits ethical drug companies can obtain, denoted REGPROFIT ${ }_{j}$. 
- Cross-country reference pricing regulation: the presence $(=1)$ or absence $(=0)$ of a requirement to submit information by the manufacturer on drug prices in other countries (Dukes, Haaijer-Ruskamp, de Jonckheere, \& Rietveld, 2003), denoted $R E G C R O S S_{j}$.

- Therapeutic reference pricing regulation: whether health regulators generate a reference price for a cluster of drugs that have therapeutic similarities $(=1)$ or not $(=0)$, above which price the patient is surcharged (Danzon \& Ketcham, 2003), denoted $R E G R E F_{j}$;

- Pharmaco-economic evidence regulation: whether health regulators ask for some proof of the drug's cost effectiveness before launch $(=1)$ or not $(=0)$ (Dickson, Hurst, \& Jacobzone, 2003; Dukes et al., 2003; Garber \& Phelps, 1997), denoted REGPHARMACO;

- Strength of patent protection regulation: an index based on 5 levels of patent laws ranging from 0 to 5 for each country, from weak to strong patent protection (Ginarte \& Park, 1997; Park \& Wagh, 2000), denoted REGPATENT . $_{j}$

As to market size of a country, ideally we would control for the incidence of the disease in each country. However, given that such data is not available across countries, we control for population size at the time of launch $\left(P O P_{j}\right)$, measured by the natural logarithm of the number of inhabitants of country $j$. Countries with a larger population size, ceteris paribus, contain more people suffering from a specific disease, than countries with a smaller population size. We also include the natural logarithm of health expenditures per capita in country $j\left(H E A L T H E X P_{j}\right)$ at the time of launch. We obtained information on both variables from the Worldbank.

We obtained data on the dimensions of a country's national culture from Hofstede (1980 and 2001), denoted as follows: uncertainty avoidance $\left(U A I_{j}\right)$, masculinity $\left(M A S_{j}\right)$, individualism $\left(I D V_{j}\right)$, and power distance $\left(P D I_{j}\right)$. To control for the effect of competition on launch window 
and launch price, we constructed a Herfindahl-Hirschman index $\left(C O M P_{i j}\right)$ for drug $i$ in country $j$. This index is constructed by summing the squared market shares (MS) (based on revenues in the IMS Health data we obtained) of the $m$ drugs in the same ATC4 category as drug $i$, at the time of launch of drug $i$ in country $j\left(C O M P_{i j}=\sum_{m=1}^{M} M S_{m j}^{2}\right)$. A high Herfindahl-Hirschman index indicates that there is little competition for drug $i$ in country $j$. We operationalize the home country of the company launching a specific drug $i$ in country $j\left(H O M E_{i j}\right)$ as a dummy variable $(=1$, if the company's headquarter is located in the country of launch $j, 0$ otherwise) (Danzon et al., 2005; Kyle, 2006 and 2007).

The variable $S U M M E R_{i j}$ is a dummy variable that captures whether the launch of drug $i$ in country $j$ occurs in the months July or August for countries in the Northern hemisphere or in the months January or February for countries in the Southern hemisphere whereas the variable $E M E A_{j}$ is a dummy variable that has the value 1 if a drug is launched in a country $j$ that is part of the European Medicines Evaluation Agency's decision zone (EMEA). A drug $i$ 's defined daily dosage $\left(D D D_{i}\right)$ in grams is the assumed average maintenance dose per day of a drug used for its main indication in adults (World Health Organization definition). We extracted the inflation rate (annual percentage change in GDP deflator) in country $j$ at the time of launch $\left(I N F L_{j}\right)$ from the Worldbank. Finally, we denote the 28 dummy variables for the 29 therapeutic classes a drug $i$ belongs to as $A T C_{i}$ (see Table 2). We treat the therapeutic class A10BG as the base category. Table 3 gives an overview of the descriptives of the aforementioned variables (for correlation matrix, see Table A.1. in Appendix A). 


\subsection{Descriptive Statistics}

Table 4 provides an overview of the countries' descriptives with regard to launch window and launch price. The first column in Table 4 contains the countries we study, classified by world region. These countries are ranked from early to late within world regions based on the launch window (from early to late launch) in the second column. To calculate mean launch leads and lags, we used the following procedure. We first computed the mean launch window for each drug across the countries. Then, we subtracted this mean launch window of the drug from each country-specific launch window for that drug. Third, we averaged these country-specific launch windows over all drugs launched in each specific country to obtain mean leads and lags for each specific country. A mean lead (-) indicates that drugs are typically launched early in a country, while a mean lag $(+)$ indicates that drugs are typically launched late in a country.

\begin{tabular}{ll}
\hline Variable (abbreviation used in Table A.1.) & Average [Range] \\
\hline Launch Price in U.S. Dollars in Grams (V1) & $28.051[0.35 ; 3,945,160]$ \\
Launch Window (V2) & $21.86[0 ; 128]$ \\
Ex-Manufacturer Price Regulation (V3) & $0.62[0 ; 1]$ \\
Profit Control Regulation (V4) & $0.19[0 ; 1]$ \\
Cross-Country Reference Pricing Regulation (V5) & $0.69[0 ; 1]$ \\
Therapeutic Reference Pricing Regulation (V6) & $0.41[0 ; 1]$ \\
Pharmaco-Economic Evidence Regulation (V7) & $0.49[0 ; 1]$ \\
Strength of Patent Protection (V8) & $3.62[1.98 ; 5]$ \\
Population Size (V9) & $17,192,779[404,335 ; 294,267,566]$ \\
Health Expenditures per Capita (V10) & $1,361[126 ; 6,015]$ \\
Uncertainty Avoidance (V11) & $68.93[23 ; 112]$ \\
Masculinity (V12) & $53.06[5 ; 95]$ \\
Individualism (V13) & $57.70[8 ; 91]$ \\
Power Distance (V14) & $49.66[11 ; 94]$ \\
Competition (V15) & $0.61[0.13 ; 1]$ \\
Firm's Home Country (V16) & $0.03[0 ; 1]$ \\
EMEA (V17) & $0.54[0 ; 1]$ \\
Summer (V18) & $0.14[0 ; 1]$ \\
Daily Dosage in Grams (V19) & $0.23\left[1.80 \times 10^{-5} ; 6.75\right]$ \\
Inflation (V20) & $3.80[-23 ; 94]$ \\
\hline
\end{tabular}

Table 3: Descriptives of variables

\footnotetext{
${ }^{5}$ The high maximum launch price in U.S. dollars per gram corresponds to the price of a drug for which the dosage is very small. In the empirical analysis, we use the natural logartithm of launch price. We check for the effect of potential outliers which we report in section 5.1.
} 


\begin{tabular}{|c|c|c|}
\hline World Region and Countries & $\begin{array}{c}\text { Mean Lead (-) or Lag (+) in Launch } \\
\text { Window (in Months) }\end{array}$ & $\begin{array}{c}\text { \% Deviation from Mean Price at } \\
\text { Launch per Gram }\end{array}$ \\
\hline North America & -8.95 & 37.87 \\
\hline U.S. & -17.17 & 37.79 \\
\hline Canada & -7.50 & -1.57 \\
\hline Puerto Rico & -7.21 & 93.09 \\
\hline Mexico & -3.94 & 22.16 \\
\hline Western Europe & -5.81 & -8.15 \\
\hline Germany & -15.59 & -9.17 \\
\hline Denmark & -10.65 & -5.35 \\
\hline U.K. & -9.82 & -0.14 \\
\hline Austria & -9.13 & -9.92 \\
\hline Switzerland & -8.97 & 0.21 \\
\hline Ireland & -8.08 & -5.22 \\
\hline Sweden & -7.11 & -8.48 \\
\hline Netherlands & -6.95 & -6.93 \\
\hline Finland & -6.44 & -4.39 \\
\hline Norway & -5.87 & 3.83 \\
\hline Spain & -4.03 & -17.22 \\
\hline Belgium & -3.45 & -13.61 \\
\hline Luxemburg & -2.22 & -12.78 \\
\hline Portugal & -1.66 & -11.47 \\
\hline Italy & -1.01 & -13.26 \\
\hline France & -0.46 & -12.44 \\
\hline Greece & 2.06 & -12.21 \\
\hline South America & -0.43 & 7.93 \\
\hline Brazil & -6.79 & 14.43 \\
\hline Argentina & -6.36 & 0.89 \\
\hline Colombia & -3.12 & 33.67 \\
\hline Chile & -2.27 & -8.19 \\
\hline Venezuela & 1.97 & 17.49 \\
\hline Uruguay & 3.95 & 12.72 \\
\hline Peru & 4.29 & -4.20 \\
\hline Ecuador & 4.91 & -3.39 \\
\hline Oceania & 0.10 & -8.02 \\
\hline Australia & -1.55 & -11.82 \\
\hline New Zealand & 1.75 & -4.21 \\
\hline Asia & 5.16 & 11.01 \\
\hline Philippines & -2.17 & -12.15 \\
\hline Japan & 6.89 & 47.89 \\
\hline Korea & 10.75 & -2.71 \\
\hline Eastern Europe & 8.74 & -1.62 \\
\hline Czech Republic & 5.03 & 1.58 \\
\hline Estonia & 5.21 & -3.51 \\
\hline Hungary & 5.68 & -5.54 \\
\hline Poland & 8.91 & 1.71 \\
\hline Latvia & 9.55 & -5.78 \\
\hline Slovakia & 12.77 & 0.78 \\
\hline Lithuania & 14.02 & -0.61 \\
\hline Africa and the Middle East & 14.51 & -13.31 \\
\hline Kuwait & 4.42 & -1.81 \\
\hline South Africa & 5.14 & -26.11 \\
\hline United Arabic Emirates & 6.49 & 4.33 \\
\hline Lebanon & 6.77 & -16.32 \\
\hline Jordan & 12.37 & -7.89 \\
\hline Egypt & 17.86 & -29.10 \\
\hline Saudi Arabia & 19.40 & -13.37 \\
\hline Morocco & 20.88 & -8.67 \\
\hline Tunisia & 37.28 & -20.82 \\
\hline
\end{tabular}

Table 4: Mean lead (-) or lag (+) in launch window and \% deviation from mean price at launch by world region and country 
Column 3 in Table 4 shows the countries' deviation from the mean launch price across drugs. To calculate these deviations, we, first, computed the mean launch price for each drug across the countries. Then, within each drug, we computed the percentage deviation of the country-specific price from the mean price over all countries. Finally, we averaged these percentage deviations for each specific country over all drugs launched in that country. A negative deviation means that a drug is typically launched at a relatively low price in a country whereas a positive deviation indicates that a drug is typically launched at a relatively high price in a country.

Our study is the first to give an overview of both mean launch lead and lag times and mean launch price deviations across such a broad spectrum of categories and countries, which leads to several new descriptive insights.

First, we find that the U.S., Germany, and Denmark experience the largest lead in launch. Tunisia, Morocco, and Saudi Arabia experience the largest lag in launch. North America and Western Europe show similar (small) launch delays. Launch delays are largest in Eastern Europe, Africa and the Middle East. There is a marked difference in launch timing between Western Europe (fast) and Eastern Europe (slow), despite many of these launches having occurred recently. Puerto Rico, Japan, and the U.S. have the largest positive deviation from the average launch price worldwide whereas Egypt, South Africa, and Tunisia show the largest negative deviation from the worldwide average launch price. North America, South America, and Asia show positive deviations from the worldwide average launch price, while the other world regions - including Europe - show a negative deviation from the average launch price worldwide. 


\section{Model}

Let $L W_{i j}^{*}$ be the launch window of drug $i$ in country $j$ and let $L P_{i j}^{*}$ be the natural logarithm transformed ex-manufacturer price per gram at launch of drug $i$ in country $j$. We do not always observe the actual values of $L W_{i j}^{*}$ and $L P_{i j}^{*}$ since right censoring is present. Observed values are denoted by $L W_{i j}$ and $L P_{i j}$. Censoring occurs for the drug-country combinations for which we do not observe a launch at the end of our observation window. Denote $C_{i j}$ the censoring time, being the time between the end of the observation period and the drug-country specific launch date. For the observed launch window, we have that

$$
\begin{cases}L W_{i j}=L W_{i j}^{*} & \text { if } L W_{i j}^{*} \leq C_{i j}, \\ L W_{i j}=C_{i j} & \text { otherwise. }\end{cases}
$$

Furthermore, the launch price $L P_{i j}$ is only observed on the selected sample for which $L W_{i j}^{*} \leq C_{i j}$, and there $L P_{i j}=L P_{i j}^{*}$.

We have the following set of simultaneous equations:

$$
\left\{\begin{array}{l}
L W_{i j}^{*}=\alpha_{1} L P_{i j}^{*}+\alpha_{2}\left(L P_{i j}^{*}\right)^{2}+\delta^{\prime} \mathbf{Z}_{i j 1}+u_{i j 1} \\
L P_{i j}^{*}=\beta_{1} L W_{i j}^{*}+\beta_{2}\left(L W_{i j}^{*}\right)^{2}+\gamma^{\prime} \mathbf{Z}_{i j 2}+u_{i j 2}
\end{array}\right.
$$


The vector $\mathbf{Z}_{i j 1}$ contains the exogenous variables for the launch window equation and $\mathbf{Z}_{i j 2}$ contains the exogenous variables for the launch price equation. The error terms $u_{i j 1}$ and $u_{i j 2}$ are allowed to be correlated. Following Garen (1984), we consider $L W_{i j}^{*}$ and $L P_{i j}^{*}$ as endogenous variables. Indeed, the firm and the regulator may both select the launch window with the goal of influencing the launch price, and the level of launch price with the goal of influencing the launch window. The omitted variables in $u_{i j 1}$ include non-observable strategic variables used by the firm and the regulator to select the optimal value of $L W_{i j}^{*}$. One may expect that these strategic variables are correlated with the launch price. The omitted variables in $u_{i j 2}$ then include nonobservable strategic variables used by the firm and the regulator to select the optimal value of $L P_{i j}^{*}$. Similarly, one may expect that these strategic variables are correlated with the launch window. The inclusion of the quadratic terms in (2) and (3) allows testing of $\mathrm{H} 1$ and $\mathrm{H} 2$. We will test the robustness of our findings through other parametric and non-parametric specifications. To account for the endogeneity, we estimate the system of equations (2) and (3) using a three stage least squares (3SLS) procedure, as in Bayus, Kang, \& Agarwal (2007). Additionally, we correct for right-censoring and selectivity using the same procedure as in Vella (1993) or Wooldridge (2002).

To estimate the structural launch window equation (2), we first estimate the reduced form of the launch price equation by a Tobit regression of the second type (to account for the fact that we only observe prices if the drug has already been launched). This launch price equation contains two variables that influence launch price but not launch window, namely $D D D_{i}$ and $I N F L_{j}$, which serve as instruments for the launch price in the launch window equation. The 
Sargent test does not lead to rejection of the validity of these instruments $(p=0.46)$. We add the generalized residuals of the reduced launch price equation as a correction term to equation (2). We validated the strength of the instruments by comparing Tobit regression models of launch window on the exogenous variables with and without the instruments $D D D_{i}$ and $I N F L_{j}$. The corresponding likelihood ratio test demonstrated these instruments to be significant (LR=625.11, $\mathrm{p}<0.01)$. The inclusion of instruments led to a relative increase in pseudo R-squared of $10 \%$.

To estimate the structural launch price equation (3), we first estimate the reduced form of the launch window equation by a Tobit regression of the first type (to account for the right censoring). This launch window equation contains two variables that influence launch window but not launch price, namely $S U M M E R_{i j}$ and $E M E A_{j}$, which serve as instruments for the launch window in the launch price equation. The Sargent test does not indicate a rejection of the validity of these instruments $(\mathrm{p}=0.75)$. We add the generalized residuals of the reduced launch window equation as a correction term to equation (3). We tested for the strength of the instruments by computing the (pseudo) R-squared of the regression models of launch delay on the exogenous variables with and without the instruments $S U M M E R_{i j}$ and $E M E A_{j}$. The corresponding likelihood ratio test demonstrated these instruments to be significant $(\mathrm{LR}=153.80, \mathrm{p}<0.01)$. The inclusion of instruments led to a relative increase in pseudo R-squared of 5\%.

Replacing the vectors $\mathbf{Z}_{i j 1}$ (in equation 2) and $\mathbf{Z}_{i j 2}$ (in equation 3) by the exogenous variables leads then to equation (4) and equation (5), respectively 


$$
\begin{aligned}
& L W_{i j}=\delta_{0}+a_{1} \text { PP }_{i j}+a_{2} L_{i j}^{2}+\phi_{1} v_{L P}+ \\
& \delta_{1} \text { REGPRICECONTROL }_{j}+\delta_{2} \text { REGPROFIT }_{j}+\delta_{3} \text { REGCROSS }_{j}+\delta_{4} \text { REGREF }_{j}+ \\
& \delta_{5} \text { REGPHARMACO }_{j}+\delta_{6} \text { REGPATENT }_{j}+\delta_{7} \text { POP }_{j}+\delta_{8} \text { HEALTHEXP }_{j}+\delta_{9} \text { UAI }_{j}+ \\
& \delta_{10} \text { MAS }_{j}+\delta_{11} \text { IDV }_{j}+\delta_{12} \text { PDI }_{j}+\delta_{13} \text { COMP }_{i j}+\delta_{14} \text { HOME }_{i j}+\delta_{15} \text { SUMMER }_{i j}+\delta_{16} \text { EMEA }_{j}+ \\
& \sum_{i=1}^{28} \xi_{i} \text { ATC }_{i}+\eta_{i j 1}
\end{aligned}
$$

$$
\begin{aligned}
& L P_{i j}=\gamma_{0}+b_{1} L_{i j}+b_{2} L W_{i j}^{2}+\theta_{1} v_{L W}+ \\
& \gamma_{1} \text { REGPRICECONTROL }_{j}+\gamma_{2} \text { REGPROFIT }_{j}+\gamma_{3} \text { REGCROSS }_{j}+\gamma_{4} \text { REGREF }_{j}+ \\
& \gamma_{5} \text { REGPHARMACO }_{j}+\gamma_{6} \text { REGPATENT }_{j}+\gamma_{7} \text { POP }_{j}+\gamma_{8} \text { HEALTHEXP }_{j}+\gamma_{9} U A I_{j}+ \\
& \gamma_{10} \text { MAS }_{j}+\gamma_{11} I D V_{j}+\gamma_{12} \text { PDI }_{j}+\gamma_{13} \text { COMP }_{i j}+\gamma_{14} \text { HOME }_{i j}+\gamma_{15} \text { DDD }_{i}+\gamma_{16} \text { INFL }_{j}+ \\
& \sum_{i=1}^{28} \zeta_{i} \text { ATC }_{i}+\eta_{i j 2}
\end{aligned}
$$

where $v_{L P}$ and $v_{L W}$ represent the generalized residuals or the selectivity variables. The use of generalized residuals is equivalent to the control function approach; the terms $\phi_{1} v_{L P}$ and $\theta_{1} v_{L W}$ in (4) and (5) are the control functions (see Petrin and Train (2010) for another application of control functions). The system of equations (4) and (5) is then jointly estimated as a system of equations using Generalized Least Squares. We also included random country effects in the equations to account for the fact that there are repeated observations across countries for most drugs. These random effects thus introduce a correlation, called the within-group correlation, between the error terms corresponding to the same country.

In sum, the coefficients $a_{1}$ and $a_{2}$ allow us to test for hypothesis 1 (the causal effect of launch price on launch window while controlling for the joint determination of launch window and launch price), whereas the coefficients $b_{1}$ and $b_{2}$ allow us to test for hypothesis 2 (the causal effect of launch window on launch price while controlling for the joint determination of launch 
window and launch price). The variables $v_{L W}$ and $v_{L P}$ capture the simultaneous determination of launch window and launch price. These variables measure whether launch window is strategically selected as a function of launch price and vice versa.

For clarification, note that the expressed non-linear relationships in equations (4) and (5) are not each other's flip side. Even in a simple regression context, with a fitted regression equation $\hat{Y}=a+b X$, it is not true that a regression of $\mathrm{X}$ on $\mathrm{Y}$ yields as estimated regression equation $\hat{X}=(Y-a) / b$. Thus, the estimated slope of regressing $\mathrm{Y}$ on $\mathrm{X}$ is not the inverse of the estimated slope of regressing $\mathrm{X}$ on $\mathrm{Y}$. If there is only one explanatory variable, the sign of the slopes will be equal, but when controlling for other variables one loses this property. In the special case of curvilinear effects, as in our case, the effects are not each other's flip side either.

\section{Results}

In Table 5, we present the explanatory variables in the first column. The second column contains the hypothesis number and the sign of the hypothesized expected effect for the launch window equation. We report the parameter estimates,their standard errors, and the significance levels for the launch window equation in the third, fourth, and fifth column. The sixth column in Table 5 shows the hypothesis number and the sign of the hypothesized effect for the launch price equation. The seventh, eight, and ninth column in Table 5 present the parameter estimates, their standard errors, and the significance levels for the launch price equation. We find evidence for random country effects in the launch window equation because of an intra-country correlation coefficient of $8 \%$ whereas we do not find this evidence for the launch price equation. We first 
discuss the results of the launch window equation and we then turn to the results of the launch price equation.

Consistent with hypothesis one (H1), we find a U-shaped effect of launch price on launch window $\left(a_{1}=-5.65, \mathrm{p}<0.01\right.$ and $\left.a_{2}=0.33, \mathrm{p}<0.01\right)$. This relation is depicted graphically in Figure 1, based on the full model coefficients, and within our observation window ${ }^{6}$. The values of the exogenous variables are set at their average value across the sample. Figure 1 shows that on average, the launch window is smallest at $\operatorname{Ln}$ (launch price) $=8.63$ (standard error of 1.08). This means that the launch window is smallest at a launch price that deviates $53 \%$ from the lowest price point.

The effect of ex-manufacturer price regulation is non-significant $(\mathrm{p}=0.15)$ although it does have the expected positive sign $(\mathrm{H} 3 \mathrm{a})$. As expected, profit regulation $\left(\delta_{2}=16.07, \mathrm{p}<0.01\right)$ has a positive influence on launch window (H4a).

The effect of cross-country reference pricing regulation is not significant (H5a).

Countries with therapeutic reference pricing regulation $\left(\delta_{4}=4.19, \mathrm{p}<0.05\right)$ and pharmacoeconomic evidence regulation $\left(\delta_{5}=3.40, \mathrm{p}<0.10\right)$ experience a larger launch window (H6a and $\mathrm{H7a}$ ) whereas countries with a stronger patent protection have a smaller launch window $\left(\delta_{6}=-5.96, \mathrm{p}<0.01\right)(\mathrm{H} 8 \mathrm{a})$. Next, we discuss the results for the control variables in the launch window equation. Launch occurs earlier in countries with a larger population size $\left(\delta_{7}=-\right.$ $1.98, \mathrm{p}<0.05)$ whereas health expenditures per capita significantly increase the launch window ( $\left.\delta_{8}=19.23, \mathrm{p}<0.01\right)$

\footnotetext{
6 The horizontal axis becomes negative because the launch price per gram in U.S. dollars is Ln-transformed.
} 


\begin{tabular}{|c|c|c|c|c|c|c|c|c|}
\hline & \multirow{2}{*}{$\begin{array}{c}\text { Hypothesis } \\
\text { Number } \\
\text { (Hypothesized } \\
\text { Effect) }\end{array}$} & \multicolumn{3}{|c|}{$\begin{array}{l}\text { Launch Window } \\
\text { Equation (LWE) }\end{array}$} & \multirow{2}{*}{$\begin{array}{c}\text { Hypothesis } \\
\text { Number } \\
\text { (Hypothesized } \\
\text { Effect) }\end{array}$} & \multicolumn{3}{|c|}{$\begin{array}{c}\text { Launch Price } \\
\text { Equation (LPE) }\end{array}$} \\
\hline & & Coefficient & S.E. & Sign. & & Coefficient & S.E. & Sign. \\
\hline Constant $\left(\delta_{0}, \gamma_{0}\right)$ & & -41.90 & 5.99 & $* * *$ & & 3.19 & 0.86 & $* * *$ \\
\hline Launch Price $\left(a_{1}\right)$ & & -5.65 & 0.80 & $* * *$ & & / & I & \\
\hline Launch Price*Launch Price $\left(a_{2}\right)$ & $\mathrm{H} 1(\mathrm{U})$ & 0.33 & 0.04 & $* * *$ & & I & I & \\
\hline Launch Window $\left(b_{1}\right)$ & & / & l & & & 0.03 & $5.10 \times 10^{-3}$ & $* * *$ \\
\hline Launch Window*Launch Window $\left(b_{2}\right)$ & & l & / & & $\mathrm{H} 2(\cap)$ & $-1.79 \times 10^{-4}$ & $5.89 \times 10^{-5}$ & $* * *$ \\
\hline Selectivity Variable $\left(\phi_{1}, \theta_{1}\right)$ & & 2.77 & 0.69 & $* * *$ & & -2.32 & 2.81 & \\
\hline Ex-Manufacturer Price Regulation $\left(\delta_{1}, \gamma_{1}\right)$ & $\mathrm{H} 3 \mathrm{a}(+)$ & 3.75 & 2.55 & & H3b (-) & -0.14 & 0.09 & \\
\hline Profit Control Regulation $\left(\delta_{2}, \gamma_{2}\right)$ & $\mathrm{H} 4 \mathrm{a}(+)$ & 16.07 & 3.02 & $* * *$ & $\mathrm{H} 4 \mathrm{~b}(-)$ & -0.14 & 0.11 & \\
\hline Cross-Country Reference Pricing Regulation $\left(\delta_{3}, \gamma_{3}\right)$ & H5a (-) & -3.44 & 2.45 & & $\mathrm{H} 5 \mathrm{~b}(+)$ & 0.06 & 0.12 & \\
\hline Therapeutic Reference Pricing Regulation $\left(\delta_{4}, \gamma_{4}\right)$ & H6a (+) & 4.19 & 1.92 & $* *$ & H6b (-) & -0.13 & 0.09 & \\
\hline Pharmaco-Economic Evidence Regulation $\left(\delta_{5}, \gamma_{5}\right)$ & $\mathrm{H} 7 \mathrm{a}(+)$ & 3.40 & 1.76 & $*$ & H7b (-) & -0.03 & 0.09 & \\
\hline Strength of Patent Protection $\left(\delta_{6}, \gamma_{6}\right)$ & H8a (-) & -5.96 & 1.89 & $* * *$ & $\mathrm{H} 8 \mathrm{~b}(-)$ & -0.07 & 0.09 & \\
\hline Population Size $\left(\delta_{7}, \gamma_{7}\right)$ & & -1.98 & 0.79 & $* *$ & & 0.07 & 0.04 & $*$ \\
\hline Health Expenditures per Capita $\left(\delta_{8}, \gamma_{8}\right)$ & & 19.23 & 1.75 & $* * *$ & & $-7.37 \times 10^{-3}$ & 0.09 & \\
\hline Uncertainty Avoidance $\left(\delta_{9}, \gamma_{9}\right)$ & & -0.20 & 0.06 & $* * *$ & & $-1.45 \times 10^{-3}$ & $2.82 \times 10^{-3}$ & \\
\hline Masculinity $\left(\delta_{10}, \gamma_{10}\right)$ & & 0.25 & 0.05 & $* * *$ & & $-1.71 \times 10^{-3}$ & $2.33 \times 10^{-3}$ & \\
\hline Individualism $\left(\delta_{11}, \gamma_{11}\right)$ & & -0.37 & 0.07 & $* * *$ & & $-3.62 \times 10^{-4}$ & $3.22 \times 10^{-3}$ & \\
\hline Power Distance $\left(\delta_{12}, \gamma_{12}\right)$ & & 0.33 & 0.08 & $* * *$ & & $-6.04 \times 10^{-3}$ & $3.82 \times 10^{-3}$ & \\
\hline Competition $\left(\delta_{13}, \gamma_{13}\right)$ (Reverse-scored) & & 2.57 & 2.38 & & & 0.65 & 0.24 & $* * *$ \\
\hline Firm's Home Country $\left(\delta_{14}, \gamma_{14}\right)$ & & -6.34 & 2.41 & $* * *$ & & 0.44 & 0.23 & $*$ \\
\hline $\operatorname{Summer}\left(\delta_{15}\right)$ & & -1.96 & 1.14 & $*$ & & I & I & \\
\hline $\operatorname{EMEA}\left(\delta_{16}\right)$ & & -4.01 & 2.14 & $*$ & & l & l & \\
\hline Daily Dosage $\left(\gamma_{15}\right)$ & & I & / & & & -3.08 & 0.18 & $* * *$ \\
\hline Inflation $\left(\gamma_{16}\right)$ & & / & l & & & $9.79 \times 10^{-3}$ & $8.29 \times 10^{-3}$ & \\
\hline Anatomical Therapeutic Classes $\left(\xi_{i}, \zeta_{i} ; i=1 \ldots 28\right)$ & & & & $* * *$ & & & & $* * *$ \\
\hline 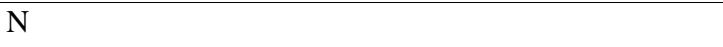 & & & & & & & 11 & \\
\hline Adjusted R-Squared & & & & & & & & \\
\hline
\end{tabular}


Table 5: Estimation results of system equation with random country effects 


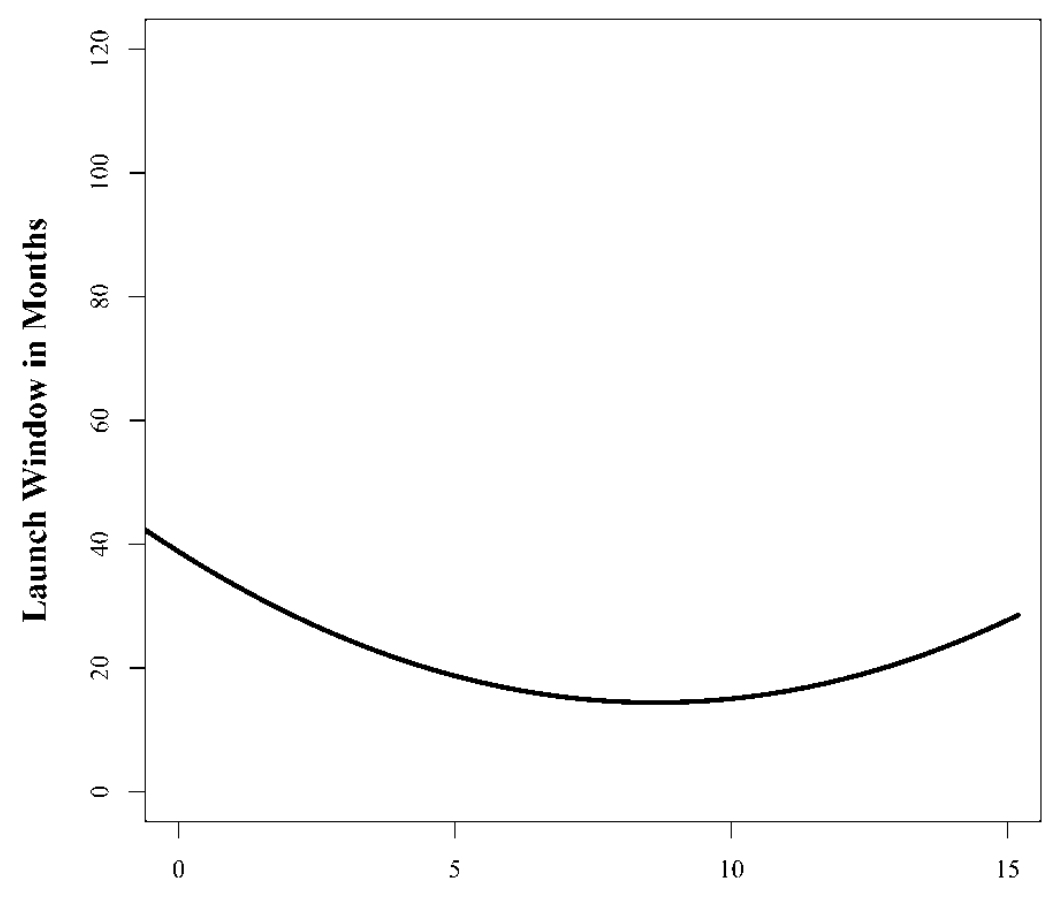

Ln(Launch price per gram in US \$)

Figure 1: The U-shaped effect of launch price on launch window

As to culture, countries high in uncertainty avoidance $\left(\delta_{9}=-0.20, \mathrm{p}<0.01\right)$ or high in individualism $\left(\delta_{11}=-0.37, \mathrm{p}<0.01\right)$ have a smaller launch window than countries low in uncertainty avoidance or low in individualism. Countries high in masculinity $\left(\delta_{10}=0.25\right.$, $\mathrm{p}<0.01)$ and power distance $\left(\delta_{12}=0.33, \mathrm{p}<0.01\right)$ have a larger launch window than countries low in masculinity and power distance. The extent of competition in the category the new drug is entering does not significantly influence the launch window. As expected, firms launch new drugs faster in their home country $\left(\delta_{14}=-6.34, \mathrm{p}<0.01\right)$. Firms also launch faster in Summer $\left(\delta_{15}\right.$ $=-1.96, \mathrm{p}<0.10)$ and in countries belonging to the EMEA zone $\left(\delta_{16}=-4.01, \mathrm{p}<0.10\right)$. The 
therapeutic category dummies are jointly significant $(\mathrm{p}<0.01)$; we do not report their specific estimates for reasons of brevity (but they are available from authors upon request).

Turning to the launch price equation, we find support for the inverted U-shaped effect of launch window on launch price, posited in $\mathrm{H} 2\left(b_{1}=0.03\right.$, p $<0.01$ and $\left.b_{2}=-1.79 \times 10^{-4}, \mathrm{p}<0.01\right)$. This relation is depicted graphically in Figure 2 (based on the full model coefficients; the values of launch window on the horizontal axis of Figure 2 remain within our observation window). Figure 2 shows that a launch window of 85 months (standard error of 17 months) is associated with the highest launch price. Because of the lag between the initial research on a compound that could become a drug, and the drug actually entering the market, Grabowski \& Kyle (2007) estimate a drug's average market exclusivity period to be approximately 11 years, but with a high variance surrounding this value. The launch window of 7 years thus seems to have face validity. After 7 years, ethical drug companies and health regulators increasingly align on lower prices for the reasons we stipulated in the theory section above. Also interestingly, the decrease in launch price between 7 and 11 years after launch is moderate. This is due to the selection of drugs of which we observe launch in a 12-year data window, according to IMS Health data storage procedures. We expect that the decrease beyond 7 years would be more expressed if we would have been able to trace drug launches over a longer data window, e.g. 20 years. 


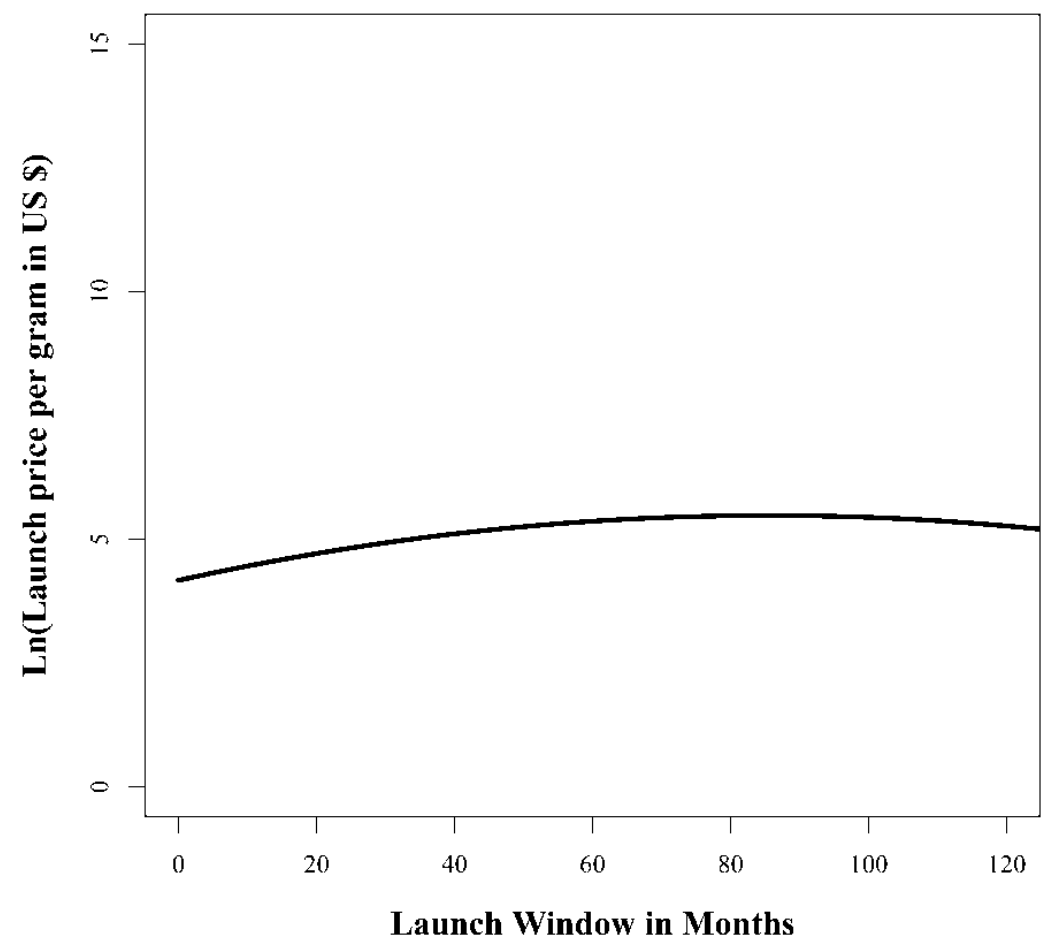

Figure 2: The inverted $U$-shaped effect of launch window on launch price

Surprisingly, regulatory restrictions - although the effect signs are in line with our expectations - do not significantly influence launch price, contrary to H3b-H8b. Stremersch and Lemmens (2009) and Ekelund and Persson (2003) found that launch prices in regulated markets may not be higher than launch prices in non-regulated markets, while prices in the regulated markets decrease at a much higher rate than prices in non-regulated markets. Danzon and Chao (2000b) have also shown the latter. Apparently, regulatory restrictions are more useful to regulators to constrain the price of mature drugs than of newly launched drugs. From conversations with the industry, we speculate that a reason may be that regulators have limited information on newly launched drugs that may guide potential price or profit caps they may 
impose. Pharmaco-economic evidence in the own country is more limited at launch than later on in a drug's life cycle. Therapeutic benefits as compared to alternatives are still partially unclear as real-life medical practice may lead to different therapeutic outcomes, as compared to outcomes in controlled clinical trials. Profits that the firm may obtain from a new drug are relatively unclear compared to the profits it may obtain from a mature drug, given the extent to which a new drug diffuses in medical practice may be uncertain.

Launch in large countries (i.e., a high population size) occurs at a higher price than in small countries $\left(\gamma_{7}=0.07, \mathrm{p}<0.10\right)$. We do not find any evidence for an effect of health expenditures per capita on launch price. As mentioned before, increasing health expenditures per capita may be indicative of both a higher willingness to provide good healthcare to citizens and a higher budget pressure, which may cancel each other out. A country's culture does not influence the launch price of a new drug.

Competition drives down launch price $\left(\gamma_{13}=0.65, \mathrm{p}<0.01\right.$; reverse-scored $)$. Firms obtain higher launch prices in their domestic market than in foreign markets $\left(\gamma_{14}=0.44, \mathrm{p}<0.10\right)$. As expected, the higher the daily dosage of a drug that is needed, the lower the price per gram of the $\operatorname{drug}\left(\gamma_{15}=-3.08, \mathrm{p}<0.01\right)$. The therapeutic category dummies are also jointly significant $(\mathrm{p}<0.01)$ in the launch price equation.

As to the selectivity variables, we find that the coefficient of this variable in the launch window equation $\left(\phi_{1}=2.77, \mathrm{p}<0.01\right)$ is significant. If launch price is higher than expected based on the values of the explanatory variables, the launch window is also larger. This finding may indicate that health regulators act strategically in delaying market access for expensive drugs, 
which is against the interests of the ethical drug company. The parameter $\theta_{1}$ in the launch price equation is non-significant.

\subsection{Robustness Checks}

We conducted many robustness checks, presented in Table 6. Adjusted R-squared measures are only given for models that are computed from the full sample.

First, we checked whether the functional form we chose (quadratic) is appropriate. We find that our model outperforms a linear model (adj. R-squared of 0.23 and 0.65 for the linear model versus 0.26 and 0.66 for the quadratic model). Our model has the same fit as a cubic model (adj. R-squared of 0.26 and 0.66 for both models). The pattern of the effect in the cubic model approaches the pattern of the effect in the quadratic model. Thus, we opt for the parsimony of the quadratic model. We also estimated equations (2) and (3) in a semi-parametric way. The model specification for the launch window equation (2) becomes:

$$
L W_{i j}^{*}=m\left(L P_{i j}^{*}\right)+\delta \mathbf{Z}_{i j 1}+u_{i j 1}
$$

with $m$ a smooth, but unknown function. This is a semi-parametric model, because the exogenous variables still enter the model in a linear way. The relationship between launch price and launch window is however completely non-parametric. We then estimate the regression function $m$ by generalized additive models. We use the same approach for the semi-parametric estimation of the price equation (equation 3). The pattern of the effect in the semi-parametric model approaches the pattern of the effect in the quadratic model.

Second, we randomly excluded specific therapeutic categories, countries and drugs. Our model results were robust to such exclusions, as shown in Table 6 for the exclusion of complete categories (results of country and drug exclusions available from the authors upon request). The 
only exception is the exclusion of ATC1 category 3 , in which case the inverted U-shaped effect of launch window on launch price turns insignificant. We also checked for potential outliers by excluding the country with the highest price for each molecule. Our results stay robust.

Third, we also examined alternate operationalizations of several variables. For instance, Table 6 shows that the model is robust to alternate measures for competition (i.e. using number of competitors instead of the Herfindahl index we mentioned earlier) and population size (i.e. only counting people older than 15 years of age). Alternate operationalizations of control variables yielded similar effects.

\begin{tabular}{lcc}
\hline Model specification & $\begin{array}{c}\text { Effect of launch price on } \\
\text { launch window U-shaped? }\end{array}$ & $\begin{array}{c}\text { Effect of launch window on } \\
\text { launch price inverted U-shaped? }\end{array}$ \\
\hline Linear model & $/$ & $/$ \\
Cubic model & Yes & Yes \\
Semi-parametric model & Yes & Yes \\
Exclusion of ATC1 category 1 & Yes & Yes \\
Exclusion of ATC1 category 2 & Yes & Yes \\
Exclusion of ATC1 category 3 & Yes & No \\
Exclusion of ATC1 category 4 & Yes & Yes \\
Exclusion of ATC1 category 5 & Yes & Yes \\
Exclusion of country with highest & Yes & Yes \\
price for each molecule & Yes & Yes \\
Nr of competitors instead of HI & Yes & Yes \\
Size of population older than 15 years & \multicolumn{2}{|c|}{} \\
instead of total population size & Rizess & \\
\hline
\end{tabular}

Table 6: Robustness checks

\section{Discussion and Implications}

This paper yields interesting insights in the complex phenomenon of international launch behavior by ethical drug firms and their interaction with health regulators. While controlling for the simultaneity in the decision on international launch timing and launch price, we find that international launch price has a U-shaped effect on launch window whereas the international 
launch window has an inverted U-shaped effect on launch price. Health regulators behave strategically in increasing a new drug's launch delay the more expensive the new drug is. Moreover, we gain further insight into factors influencing, on the one hand, launch window and, on the other hand, launch price. While regulation influences launch window, we do not find this influence of regulation on launch price. Our findings give insights to managers and public policy makers, while the limitations of our work yield opportunities for future research.

International launch window and price have an important impact on companies' bottom line (Danzon et al., 2005; Wagner \& McCarthy, 2004). Stremersch and Lemmens (2009) showed that launch window of pharmaceuticals does not influence the sales pattern. However, as we show that launch window and launch price are interrelated, launch window will influence the revenues of firms through launch price and the time the drug is on the market under patent protection. The contribution of our results to ethical drug firms primarily lies in enhancing their understanding of international launch window and price patterns. The patterns we find, inform firms on launch windows and prices that are common across countries in our sample. This descriptive information and the interconnection between launch price and launch window allows them to build more informed decisions for international market entry.

Our research can also inform public policy administrators on launch windows and launch prices, both of which are relevant to their healthcare policy. Popular press sometimes points at individual cases on how a drug was launched late in a country or how the price of a specific drug is higher in one country, as compared to other countries. For example, the anti-allergy drug Xyzall has been launched in the U.S. with a significant delay in comparison to many other countries (Global Insight, 2007). The launch price of Pfizer's statin Lipitor was $€ 0.60$ in Paris (France) whereas the launch price of that same pill was $\$ 3.98$ in Philadelphia (the U.S.) (Capell, 
2003). Typically, such stories in the popular press are very much based on a single case. For every single country, we can come up with at least one drug that was introduced very late or priced very highly. The popular press typically generalizes much beyond the single case they cite to make inference on the country's healthcare policy, often to support criticism on the latter. This study provides public policy analysts with more quantitative evidence on a broad sample of countries and categories.

Furthermore, our model can give insights into hypothetical situations as long as such situations occur within the bounds of variation observed in our data. Thus, we can gauge the effect of a change in launch window on launch price and vice versa, using the estimates for the causal effects between both decision variables we reported above, controlling for the simultaneity in the launch price and launch window decisions. For example, Lipitor's (atorvastatin) launch in 1998 in Belgium had a launch window of 15 months. If the launch of Lipitor occurred one month earlier, its launch price in Belgium would have been $2.51 \%$ (S.E. = $0.43 \%$ ) lower than its actual launch price. Thus, health regulators may not only increase patients' access to new drugs by granting earlier access but such early access may also come at a lower price. Ethical drug companies accept such lower price because they get more time to recoup their R\&D investment. A similar exercise for Lipitor in all countries, reveals that, in relative terms, the biggest launch price decrease would be in the U.K.(-3.04\%) and the smallest launch price decrease would be in Tunisia (-1.21\%). On the other hand, a $10 \%$ increase in price of Lipitor (from $\$ 70.64$ to $\$ 77.70$ ) in Belgium, would have led to a decrease in launch window with 0.25 months, which translates to 8 days (S.E. $=3$ days). A similar exercise for Lipitor in all countries reveals a decrease in launch windows between 0.22 months, which translates to 7 days (New Zealand) and 0.29 months, which translates to 9 days (Columbia). Although such calculations are 
conditional upon other variables remaining equal and are purely illustrative, we gain insight on the magnitude of the interdependencies of these two important decisions, launch timing and launch price.

\section{Limitations and Future Research}

First, our results are context-specific as the focus is on the pharmaceutical industry. Therefore, one should exert caution in generalizing beyond this research context. Whereas one can argue that this creates a narrow appeal, one should consider the economic and substantive importance of this industry (Stremersch \& Van Dyck, 2009; Stremersch, 2008).

Second, we do not specify the objective function of firms and health regulators. The reason is that it is not clear whether the objective function of health regulators is access to healthcare or controlling healthcare budgets. Although a model of the dynamic game between health regulator and ethical drug company would be of great interest, it is considered to be outside of the scope of this paper.

Third, one can easily critique the simple operationalization of the complex regulatory environment. Operationalizing the regulatory context across countries in more detail, while challenging, could be insightful. For example, further research could try to explicitly take into account the interdependencies that occur between countries because of the cross-country reference pricing regulation. We controlled for this system through a dummy variable but richer insights could be obtained by gathering data on the reference set of each country that applies such a system.

Fourth, launch window and launch price decisions are decisions that are made in a complex environment. Although we control for many variables for sake of completeness, we 
acknowledge that we may not capture all possible variables. However, given the diversity of the variables we control for and the many robustness checks we performed, we feel confident about our findings.

Fifth, while we provide evidence for variation in drugs' availability across countries and drugs' launch prices, we do not have data on the price patients actually pay (the level of "copay"). Even if a drug's price is low, patients in some countries can still be excluded from access to this drug, because of a high co-payment. Data on how much patients actually co-pay across countries would add insights, but to our knowledge, this data is unavailable at the drug-country level.

Sixth, beyond launch timing and launch price, one may consider the launch sequence of a new drug across countries. While optimizing launch sequence for new drugs is outside the scope of the present paper, it is certainly of high relevance, given cross-country spill-over (e.g. due to cross-country reference pricing) in drug prices.

Seventh, we find that the effect of regulation on drug launch prices is insignificant. While this confirms earlier findings of Stremersch and Lemmens (2009) and Ekelund and Persson (2003), we can only speculate as to the reasons why this happens (i.e. higher budget pressure for the regulator from mature drugs than from newly launched drugs). This reasoning is in line with Danzon and Chao (2000b) who show that regulation has an effect on the price evolution of the life cycle of a drug. Future research that examines the health regulator's use of regulatory restrictions to drug prices over drugs' life cycle may be very valuable as it may uncover the reasons for the patterns we discovered. However, given our focus on launch, this investigation is beyond the scope of the present paper. 
Eight, the drug prices in our model are expressed in a common denominator, namely US dollars per gram, as converted from the local currency by IMS Health in the month of launch. A formal analysis of the macro-economic influence of the exchange rate on drug prices is, while potentially interesting, beyond the scope of the present paper. Our findings are robust to the exclusion of specific countries as well as exclusion of specific time periods from the sample, alleviating concerns that our findings may be driven by countries with strong currency fluctuation in specific time periods (e.g. Brazil in 2002-2003).

Given the business and societal relevance of international launch and pricing of pharmaceuticals and the limitations of prior studies in this field, including of our present study, we expect much more work on this topic to be undertaken by scholars in both economics and marketing. 


\section{References}

Abbott, T.A. (1995). Price regulation in the pharmaceutical industry: prescription or placebo? Journal of Health Economics, 14, 551-565.

Bayus, B.L., Kang, W., \& Agarwal, R. (2007). Creating growth in new markets: A simultaneous model of firm entry and price. Journal of Product Innovation Management, 24, 139-155.

Berndt, E.R. (2000). International comparisons of pharmaceutical prices: What do we know, and what does it mean? Journal of Health Economics, 19 (2), 283-287.

Bolton, R.N., \& Myers, M.B. (2003). Price-based global market segmentation for services. Journal of Marketing, 67 (July), 108-128.

Borrell, J.R. (1999). Pharmaceutical price regulation: A study on the impact of the rate-of-return regulation in the U.K. Pharmacoeconomics, 15 (3), 291-303.

Burgess, S.M., \& Steenkamp, J.B.E.M. (2006). Marketing renaissance: How research in emerging markets advances marketing science and practice. International Journal of Research in Marketing, 23 (4), 337-356.

Capell, K. (2003, February 17). Commentary: Europe pays a high price for cheap drugs. Business Week. URL: http://www.businessweek.com/magazine/content/03_07/b3820139_mz034.htm. Last accessed on April 27th 2011.

Chandy, R.K., \& Tellis, G.J. (1998). Organizing for radical product innovation: The overlooked role of willingness to cannibalize. Journal of Marketing Research, 35 (4), 474-487.

Chintagunta, P.K., \& Desiraju, R. (2005). Strategic pricing and detailing behavior in international markets. Marketing Science, 24 (1), 67-80.

Cohen, J., Faden, L., Predaris, S., \& Young, B. (2007). Patient access to pharmaceuticals: An international comparison. European Journal of Health Economics, 8 (3), 253-266.

Comanor, W.S., \& Schweitzer, S.O. (2007). Determinants of drug prices and expenditures. Managerial and Decision Economics, 28 (4-5), 357-370.

Danzon, P.M. (1998). The economics of parallel trade. Pharmacoeconomics, 13 (3), 293-304.

Danzon, P.M., \& Chao, L.W. (2000a). Cross-national price differences for pharmaceuticals: How large, and why? Journal of Health Economics, 19 (2), 159-195.

Danzon, P.M., \& Chao, L.W. (2000b). Does regulation drive out competition in pharmaceutical markets? Journal of Law and Economics, 43 (2), 311-357.

Danzon, P.M., \& Furukawa, M.F. (2003). Prices and availability of pharmaceuticals: Evidence from nine countries. Health Affairs, 22 (6), 521-536.

Danzon, P.M., \& Furukawa, M.F. (2006). Prices and availability of biopharmaceuticals: An international comparison. Health Affairs, 25 (5), 1353-1362.

Danzon, P.M., \& Ketcham, J. (2003). Reference pricing of pharmaceuticals for Medicare: Evidence from Germany, the Netherlands and New Zealand. NBER Working paper 10007. NBER, Cambridge, MA.

Danzon, P.M., \& Kim, J.D. (1998). International price comparisons for pharmaceuticals: Measurement and policy issues. Pharmacoeconomics, 14 (1), 115-128.

Danzon, P.M., Wang, R.Y., \& Wang, L. (2005). The impact of price regulation on the launch delay of new drugs: Evidence from twenty-five major markets in the 1990s. Health Economics, 14 (3), 269-292. 
Dawar, N., \& Parker, P. (1994). Marketing universals: Consumers' use of brand name, price, physical appearance, and retailer reputation as signals of product quality. Journal of Marketing, 58 (April), 81-95.

Dekimpe, M.G., Parker, P.M., \& Sarvary, M. (2000). Globalization: Modeling technology adoption timing across countries. Technological Forecasting and Social Change, 63 (1), $25-42$

Dickson, M., Hurst, J., \& Jacobzone, S. (2003). Survey of pharmaco-economic assessment activity in eleven countries. OECD Health Working paper. OECD, Paris, France.

DiMasi, J.A., Hansen, R.W., \& Grabowski, H.G. (2003). The price of innovation: New estimates of drug development costs. Journal of Health Economics, 22 (2), 151-185.

Dukes, M.N.G, Haaijer-Ruskamp, F.M., de Jonckheere, C.P., \& Rietveld, A.H. (2003). Drugs and money: Prices, affordability and cost containment. IOS Press, Amsterdam, the Netherlands.

Ekelund, M., \& Persson, B. (2003). Pharmaceutical pricing in a regulated market. The Review of Economics and Statistics, 85 (2), 298-306.

Eliashberg, J., \& Helsen, K. (1996). Modeling lead/lag phenomena in global marketing: The case of VCRs. Working paper. The Wharton School, University of Pennsylvania, Philadelphia, PA.

Ganesh, J., \& Kumar, V. (1996). Capturing the cross-national learning effect: An analysis of an industrial technology diffusion. Journal of the Academy of Marketing Science, 24 (4), 328-337.

Garattini, L., \& Ghislandi, S. (2007). Should we really worry about "launch delays" of new drugs in OECD countries? European Journal of Health Economics, 8 (1), 1-3.

Garber, A.M., \& Phelps, C.E. (1997). Economic foundations of cost-effectiveness analysis. Journal of Health Economics, 16 (1), 1-31.

Garen, J. (1984). The returns to schooling: A selectivity bias approach with a continuous choice variable. Econometrica, 52 (5), 1199-1218.

Giaccotto, C., Santerre, R.E., \& Vernon, J.A. (2005). Drug prices and research and development investment behavior in the pharmaceutical industry. Journal of Law and Economics, 48 (1), 195-214.

Ginarte, J.C., \& Park, W.G. (1997). Determinants of patent rights: A cross-national study. Research Policy, 26 (3), 283-301.

Global Insight. (2007, May 30). Breakthrough for UCB as Xyzall finally approved by U.S. FDA. URL http://www.ihs.com/products/global-insight/industry-economicreport.aspx?id=106598036. Last accessed on April 27th 2011.

Goldberg, P.K., \& Verboven, F. (2001). The evolution of price dispersion in the European car market. The Review of Economic Studies, 68 (4), 811-848.

Golder, P.N., \& Tellis, G.J. (1993). Pioneer advantage: Marketing logic or marketing legend? Journal of Marketing Research, 30 (2), 158-170.

Grabowski, H.G., \& Kyle, M.K. (2007). Generic competition and market exclusivity periods in pharmaceuticals. Managerial and Decision Economics, 28 (4-5), 491-502.

Gregson, N., Sparrowhawk, K., Mauskopf, J., \& Paul, J. (2005). Pricing medicines: Theory and practice, challenges and opportunities. Nature Reviews, 4, 121-130. 
Heuer, A., Mejer, M., \& Neuhaus, J. (2007). The national regulation of pharmaceutical markets and the timing of new drug launches in Europe. Kiel advanced studies Working paper 437. Kiel Institute for the World Economy, Kiel, Germany.

Hofstede, G. (1980). Culture's consequences: International differences in work-related values. Sage, Beverly Hills, CA.

Hofstede, G. (2001). Culture's consequences: Comparing values, behaviors, institutions, and organizations across nations. ( $2^{\text {nd }}$ ed.). Sage Publications, Thousand Oaks, CA.

Hultink, E.J., Griffin, A., Robben, H.S.J., \& Hart, S. (1998). In search of generic launch strategies for new products. International Journal of Research in Marketing, 15 (3), 269285.

Huttin, C. (1999). Drug price divergence in Europe: Regulatory aspects. Health Affairs, 18 (3), 245-249.

Jack, A. (2007, April 18). Companies international: Cautious drug makers delay launches. Financial Times.

Jacobzone, S. (2000). Pharmaceutical policies in OECD countries: Reconciling social and industrial goals. OECD Labour Market and Social Policy - Occasional papers 40. OECD, Paris, France.

Kalish, S., Mahajan, V. \& Muller, E. (1995). Waterfall and sprinkler new-product strategies in competitive global markets. International Journal of Research in Marketing, 12 (2), 105 119.

Kanavos, P. (2001). Overview of pharmaceutical pricing and reimbursement regulation in Europe. Working paper. LSE Health, London, U.K.

Kyle, M.K. (2006). The role of firm characteristics in pharmaceutical product launches. Rand Journal of Economics, 73 (3), 602-618.

Kyle, M.K. (2007). Pharmaceutical price controls and entry strategies. The Review of Economics and Statistics, 89 (1), 88-99.

Lanjouw, J.O. (2005). Patents, price controls and access to new drugs: How policy affects global market entry. NBER Working paper 11321. NBER, Cambridge, MA.

Libai, B., Muller, E., \& Peres, R. (2005). The role of seeding in multi-market entry. International Journal of Research in Marketing, 22 (4), 375-393.

Lu, Z.J., \& Comanor, W.S. (1998). Strategic pricing of new pharmaceuticals. The Review of Economics and Statistics, 80 (1), 108-118.

McAlister, L., Bazerman, M.H., \& Fader, P. (1986). Power and goal-setting in channel negotiations. Journal of Marketing Research, 23 (3), 228-236.

Michaut, A. (2004). Consumer response to innovative products: With application to foods. PhD thesis. Wageningen University.

Morton, F.M.S. (1999). Entry decisions in the generic pharmaceutical industry. Rand Journal of Economics, 30 (3), 421-440.

Mossialos, E., Mrazek, M., \& Walley, T. (2004). Regulating pharmaceuticals in Europe: Striving for efficiency, equity and quality. Berkshire, England: Open University Press for the World Health Organization on behalf of the European Observatory on Health Systems and Policies.

Novartis. (2004, June 21). Pricing and reimbursement of pharmaceuticals. Company Report.

Park, W.G., \& Wagh, S. (2000). Index of Patent Rights. In: Economic Freedom of the World Annual Report. Fraser Institute, Vancouver, BC. 
Petrin, A., \& Train, K. (2010). A control function approach to endogeneity in consumer choice models. Journal of Marketing Research, 47 (1), 3-13.

PhRMA (Pharmaceutical Research and Manufacturers of America). (2004). Foreign government pharmaceutical price and access controls. Submission by the Pharmaceutical Research and Manufacturers of America to the U.S. Department of Commerce.

Rapp, R.T., \& Lloyd, A. (1994). "Civilized" pharmaceutical price regulations: Can the U.S. have it too? Regulation, 17 (2), 72-82.

Ridley, D.B. (2007). International price comparisons for novel and follow-on drugs. Value in Health, 10 (6), 510-511.

Rojas, M. (2009). Price discrimination by pharmaceutical companies across Central American countries. International Journal of Pharmaceutical and Healthcare Marketing, 3 (2), 118-136.

Shankar, V., Carpenter, G.S., \& Krishnamurthi, L. (1998). Late mover advantage: How innovative late entrants outsell pioneers. Journal of Marketing Research, 35 (1), 54-70.

Shankar, V., Carpenter, G.S., \& Krishnamurthi, L. (1999). The advantages of entry in the growth stage of the product life cycle: An empirical analysis. Journal of Marketing Research, 36 (2), 269-276.

Sietsema, W.K. (2006). Product pipelines and pharmaceutical risk management in the new era of strict regulatory scrutiny. International Journal of Pharmaceutical Medicine, 20 (2), 99106.

Sood, A., \& Stremersch, S. (2010). Deviation among technology reviews: An informative enrichment of technology evolution theory for marketing. ERIM Report Series Reference Number ERS-2010-005-MKT.

Stremersch, S. (2008). Health and marketing: The emergence of a new field of research. International Journal of Research in Marketing, 25 (Special Issue), 229-233.

Stremersch, S., \& Lemmens, A. (2009). Sales growth of new pharmaceuticals across the globe: The role of regulatory regimes. Marketing Science, 28 (4), 690-718.

Stremersch, S., \& Tellis, G.J. (2004). Understanding and managing growth of new products. International Journal of Research in Marketing, 21 (4), 421-438.

Stremersch, S., \& Van Dyck, W. (2009). Marketing of the life sciences: A new framework and research agenda for a nascent field. Journal of Marketing, 73 (4), 4-30.

Tellis, G.J., Stremersch, S., \& Yin, E. (2003). The international takeoff of new products: The role of economics, culture, and country innovativeness. Marketing Science, 22 (2), 188208.

Urban, G.L., \& Hauser, J.R. (1993). Design and marketing of new products. Prentice-Hall, Englewood Cliffs, NJ.

Urch. (2001a). Global pharmaceutical pricing: Strategic issues and pharmaceutical guidelines. Urch Publishing Ltd, London, U.K.

Urch. (2001b). Emerging pharmaceutical markets: Potential and problems. Urch Publishing Ltd, London, U.K.

Urch. (2002). The pharmaceutical pricing and reimbursement systems of Central and Eastern Europe. Urch Publishing Ltd, London, U.K.

Urch. (2005). The guide to pharmaceutical pricing and reimbursement systems: Western Europe. Urch Publishing Ltd, London, U.K. 
Vakratsas, D., \& Kolsarici, C. (2008). A dual-market diffusion model for a new prescription pharmaceutical. International Journal of Research in Marketing, 25 (4), 282-293.

Van den Bulte, C. (2000). New product diffusion acceleration: Measurement and analysis. Marketing Science, 19 (4), 366-380.

Vella, F. (1993). A simple estimator for simultaneous models with censored endogenous regressors. International Economic Review, 34 (2), 441-457.

Vernon, J.A., Golec, J.H., \& Keener Hughen, W. (2006). The economics of pharmaceutical price regulation and importation: Refocusing the debate. American Journal of Law and Medicine, 32 (2-3), 175-192.

Wagner, J.L., \& McCarthy, E. (2004). International differences in drug prices. Annual Review of Public Health, 25 (1), 475-495.

Wall Street Journal. (2006, September 12). BMS CEO Leaves.

Weber, B.A., Roberts, B.L., \& McDougall Jr, G.J. (2002). Exploring the efficacy of support groups for men with prostate cancer. Geriatric Nursing, 21 (5), 250-253.

Wooldridge, J. (2002). Econometric Analysis of Cross-Section and Panel Data. MIT Press, Cambridge, MA.

Wuyts, S., Dutta, S., \& Stremersch, S. (2004). Portfolios of interfirm agreements in technologyintensive markets: Consequences for innovation and profitability. Journal of Marketing, $68(2), 88-100$.

The authors acknowledge the data support of IMS Health, and the intellectual stimulation of Servaas Buijs in particular. 


\section{Appendix A}

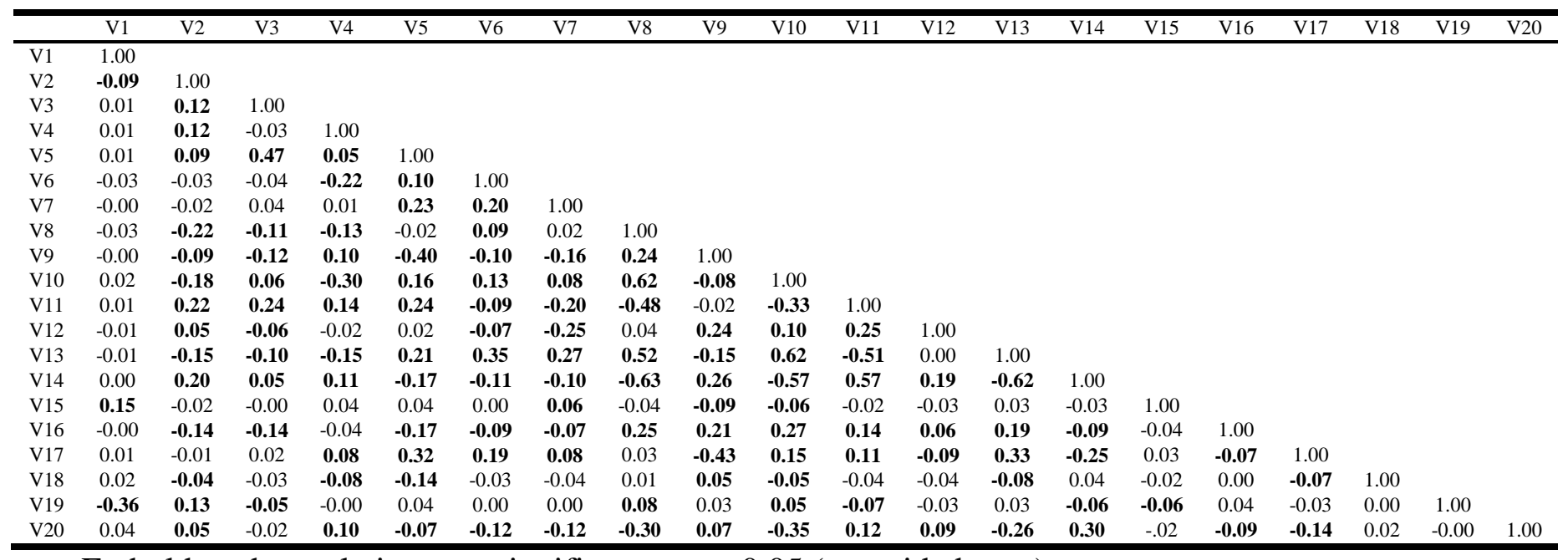

Emboldened correlations are significant at $\mathrm{p}<0.05$ (two-sided tests).

Table 3 in section 3.3. represents the labels of the variables used in this matrix. This correlation matrix shows correlations between the variables as they are operationalized and included in the model.

Table A.1. Correlation matrix 


\section{Publications in the Report Series Research* in Management}

\section{ERIM Research Program: "Marketing"}

\section{1}

Nonmetric Unfolding of Marketing Data: Degeneracy and Stability

Michel van de Velden, Alain De Beuckelaer, Patrick J.F. Groenen, and Frank M.T.A. Busing ERS-2011-006-MKT

http://hdl.handle.net/1765/22725

The Bright Side and Dark Side of Embedded Ties In Business-to-Business Innovation

Corine S. Noordhoff, Kyriakos Kyriakopoulos, Christine Moorman, Pieter Pauwels, and Benedict G.C. Dellaert ERS-2011-008-MKT

http://hdl.handle.net/1765/22813

The Global Entry of New Pharmaceuticals: A Joint Investigation of Launch Window and Price Isabel Verniers, Stefan Stremersch, and Christophe Croux

ERS-2011-010-MKT

http://hdl.handle.net/1765/23488

* A complete overview of the ERIM Report Series Research in Management: https://ep.eur.nl/handle/1765/1

ERIM Research Programs:

LIS Business Processes, Logistics and Information Systems

ORG Organizing for Performance

MKT Marketing

F\&A Finance and Accounting

STR Strategy and Entrepreneurship 